NISTIR 89-3913

\title{
INTERLABORATORY COMPARISON OF THE GUARDED HORIZONTAL PIPE-TEST APPARATUS
}

Precision of ASTM Standard Test Method C-335 Applied to Mineral-Fiber Pipe Insulation

David R. Smith

National Institute of Standards and Technology

(formerly National Bureau of Standards)

U.S. Departiment of Commerce

Boulder, Colorado 80303-3328

April 1989 

NISTIR 89-3913

\section{INTERLABORATORY COMPARISON \\ OF THE GUARDED HORIZONTAL \\ PIPE-TEST APPARATUS}

Precision of ASTM Standard

Test Method C-335 Applied

to Mineral-Fiber Pipe

Insulation

David R. Smith

Chemical Engineering Science Division

Center for Chemical Engineering

National Institute of Standards and Technology

Boulder, Colorado 80303-3328

April 1989

Sponsored, in part, by

U.S. Department of Energy

Oak Ridge National Laboratory

Oak Ridge, Tennessee 37830

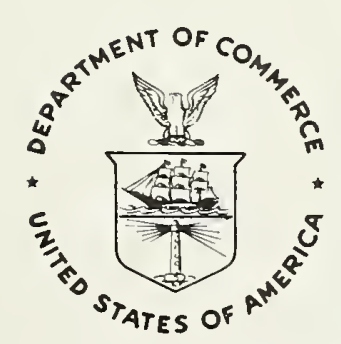

U.S. DEPARTMENT OF COMMERCE, Robert A. Mosbacher, Secretary

NATIONAL INSTITUTE OF STANDARDS AND TECHNOLOGY, Raymond G. Kammer, Acting Director 

LIST OF TABLES $\ldots \ldots \ldots \ldots \ldots \ldots \ldots \ldots \ldots \ldots \ldots \ldots$

LIST OF FIGURES $\ldots \ldots \ldots \ldots \ldots \ldots \ldots \ldots \ldots \ldots \ldots \ldots \ldots \ldots \ldots$

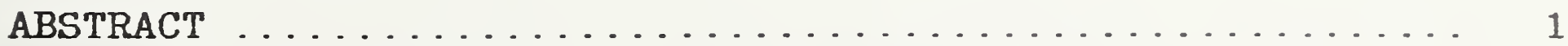

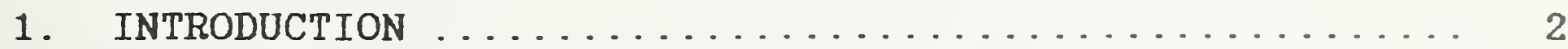

2. COMPARISON OF THE GUARDED-HOT-PLATE AND

PIPE-TEST METHODS ................. 3

a. The Guarded Hot Plate ................... 3

b. The Horizontal Pipe-Test Apparatus ............ 5

3. SCOPE .............................. 8

4. PARTICIPANTS AND APPARATUSES ................ 9

5. SPECIMEN CONDITIONING ........................ 10

6. THERMAL CONDUCTIVITY DATA .................. 11

7. REFERENCE EQUATIONS AND DATA ANALYSIS ........... 12

8. ESTIMATED PRECISION OF THE HPT METHOD ........... 17

9. SUMMARY AND CONCLUSIONG $\ldots \ldots \ldots \ldots \ldots \ldots \ldots \ldots \ldots$

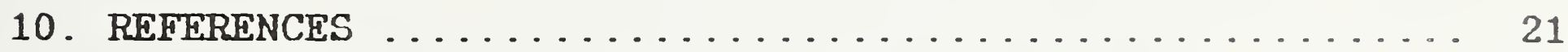

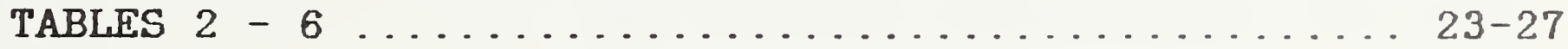

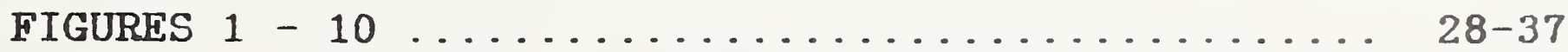





\section{LIST OF TABLES}

Table 1. Coding symbols used in figures to distinguish the seven laboratories participating in the interlaboratory comparison, and sizes of their nominally 3 -inch pipe-test apparatuses.

Table 2. Interlaboratory comparison of apparent thermal conductivity of high-temperature mineral-fiber pipe insulation measured on seven different horizontal pipe-test apparatuses. Specimens had a nominal inner diameter of $89 \mathrm{~mm}$ ( $3.5 \mathrm{in}$ ) and wall thickness of $51 \mathrm{~mm}$ ( 2 in). Measurements were performed at the ambient atmospheric pressure of each laboratory, 83 to $100 \mathrm{kPa}$ ( 630 to $760 \mathrm{Torr}$ ), and at mean temperatures from 318 to $652 \mathrm{~K}$ (113 to $12380 \mathrm{~F}$ ). The nominal density of the specimens is $90 \mathrm{~kg} / \mathrm{m}^{3}\left(5.6 \mathrm{lbm} / \mathrm{ft}^{3}\right)$. Kcalc is computed from eq (9). The standard deviation of the data set

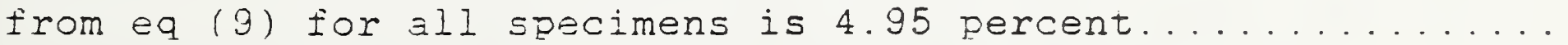

Table 3. Interlaboratory comparison of apparent thermal conductivity of high-temperature mineral-tiber pipe insulation measured on seven different horizontal pipe-test apparatuses. Kcalc is computed from eq (10), obtained by weighting each laboratory equally. The standard deviation of the data set from eq (10) for all specimens is 5.08 percent....

Table 4. Interlaboratory comparison of apparent thermal conductivity of high-temperature mineral-fiber pipe insulation. This set of specimens is restricted to only those which were conditioned by heating them to the highest temperature of measurement before data was taken. Kcalc is computed from eq (11). The standard deviation of the data set from eq (11) for conditioned specimens is 4.34 percent.... 25

Table 5. Interlaboratory comparison of apparent thermal conductivity of high-temperature mineral-fiber pipe insulation. This set of specimens is restricted to only those which were not conditioned by heating them to the highest temperature of measurement before data was taken. Kcalc is computed from eq (12). The standard deviation of the data set from eq (12) for nonconditioned specimens is 4.72

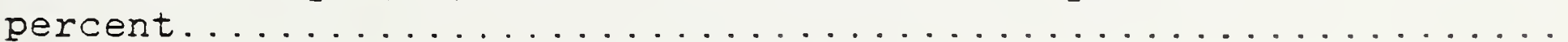


Table 6. Apparent thermal conductivity of specimens of hightemperature mineral-fiber pipe insulation that were not conditioned before they were measured. The last two columns indicate deviations of these data from the leastsquares curve, eq (11), defined by specimens that were conditioned before they were measured. The standard deviation of the data set from eq (11) for conditioned specimens

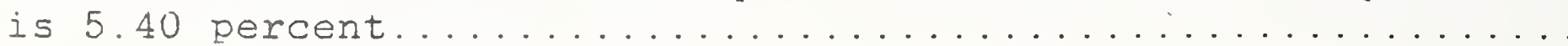




\section{LIST OF FIGURES}

Figure 1. Interlaboratory comparison of apparent thermal conductivity of mineral-fiber pipe insulation measured on the horizontal pipe-test apparatus. The nominal density of the specimens is $90 \mathrm{~kg} / \mathrm{m}^{3}\left(5.6 \mathrm{lkm} / \mathrm{ft}^{3}\right.$;. Measurements were performed in air at ambient pressure. The solid line is a plot of aq (9) for thermal conductivity as a function of temperature. Each point on this line represents the thermal conductivity determined by the local thermal gradient (vanishing temperature difference), at a point within the specimen; the temperature at that point is given by the value from the temperature axis. Each symbol represents the experimental conductivity obtained at (large) nonzero temperature differences between the boundary surfaces at Tcold and Thot. The value of conductivity at the symbol is the ratio of the integral of the conductivity function between Tcold and Thot to the corresponding temperature difference. For this reason the data points deviate from the curve when large temperature differences are used. Specimens from laboratories $1,2,4$, and $b$ were conditioned by heating specimens to the highest temperatures of measurement before taking data. Filled triangles denote repeated measurements by laboratory 2 and circled "plus" signs denote repeated measurements by labora-

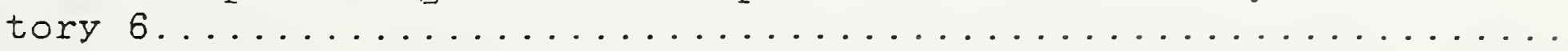

Figure 2. Deviations of apparent thermal conductivity of mineralfiber pipe insulation, as measured by all seven participants, from values calculated with eq (9), thermal conductivity as a function of temperature. Each experimental conductivity value is obtained at (large) nonzero temperature differences between the boundary surfaces at Tcold and Thot. The integral of the conductivity function is computed over the temperature interval from Teold to Thot. We compute the ratio of this integral... to the corresponding temperature difference to obtain. the mean conductivity over the interval from Tcold to Thot. The difference between the computed mean and the experimental value is the deviation. Filled triangles denote repeated measurements by laboratory 2; circled plus signs denote repeated measurements by laboratory $6 \ldots \ldots \ldots \ldots \ldots \ldots \ldots \ldots$ 
Figure 3. Interiaboratory comparison of apparent thermal conductivity of mineral-fiber pipe insulation measured on the horizontal pipe-test apparatus. Measurements were performed in air at ambient pressure. The solid line is a plot of eq (10) for thermal conductivity as a function of temperature obtained by weighting each laboratory equally. Specimens from laboratories 1, 2, 4, and 6 were conditioned by heating specimens to the highest temperatures of measurement before taking data. Filled triangles denote repeated measurements by laboratory 2 and circled "plus" signs denote repeated measurements by laboratory 6 . Please see the caption of figure 1 for an explanation of the difference between the experimental points (symbols) and the fitted conductivity

Figure 4. Deviations of apparent thermal conductivity of mineral-fiber pipe insulation, as measured by all seven participants, from values calculated with eq (10), obtained by weight-ing each laboratory equally. Filled triangles denote repeated measurements by laboratory 2 , and circled plus sigrs denote repeated measurements by laboratory 6. Please see caption of figure 2 for an

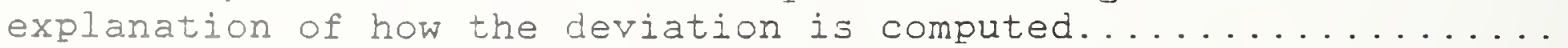

Figure 5. Interlaboratory comparison of apparent thermal conductivity of mineral-fiber pipe insulation mea measured on the horizontal pipe-test apparatus. Measurements were performed in air at ambient pressure. Specimens were conditioned by heating them to the highest temperatures of measurement before taking data. The solid line is a plot of eq (11) for thermal conductivity as a function of temperature. Please see the caption of figure 1 for an explanation of the difference between the experimental points (symbols) and the

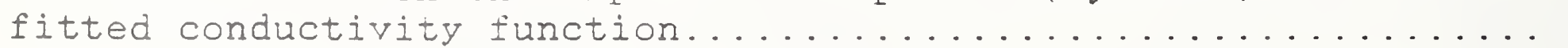

Figure 6. Deviations of apparent thermal conductivity of mineral-fiber pipe insulation, as measured after conditioning, from values calculated with eq (11). Open squares represent data from lab 4; downward-pointing triangles represent data from laboratory 6. Filled triangles are repeated measurements by laboratory 6. As before, open circles represent data of laboratory 1, and upward-pointing triangles are data of laboratory 2. Please see caption of figure 2 for an explanation of how the deviation is computed... 33 
Figure 7. Apparent thermal conductivity of specimens of mineral-fiber pipe insulation that were not conditioned before they were measured. Measurements were performed in air at ambient pressure and over the range of mean temperatures from 319 to $531 \mathrm{~K}$. The solid line is a plot of eq(12) for thermal conductivity as a function of temperature. Please see the caption of figure 1 for an explanation of the difference between the experimental points

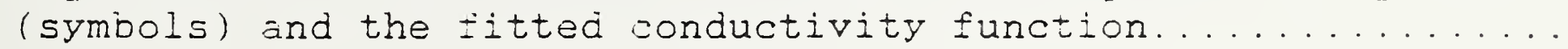

Figure 8. Deviations of apparent thermal conductivity of mineral-fiber pipe insulation, not conditioned before being measured, from values calculated with eq(12). Please see caption of figure 2 for an explanation of how the

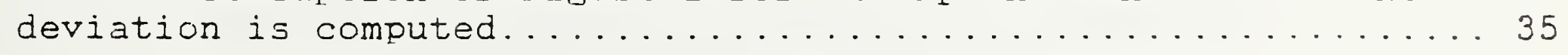

Figure 9. Apparent thermal conductivity of specimens of mineral-fiber pipe insulation that were not conditioned before they were measured. Measurements were performed in air at ambient pressure. The solid line is a plot of eq (11), thermal conductivity as a function of temperature, for specimens that were conditioned before they were measured. The position of the solid line was adjusted vertically to minimize the rms deviation of this data from the curve. Please see the caption of figure 1 for an explanation of the difference between the experimental points (symbols) and the fitted conductivity function...............36

Figure 10. Deviations of apparent thermal conductivity of mineral-fiber pipe insulation, not conditioned before being measured, from values calculated with eq (11), the relation for thermal conductivity of specimens that were conditioned. Please see caption of figure 2 for an explana-

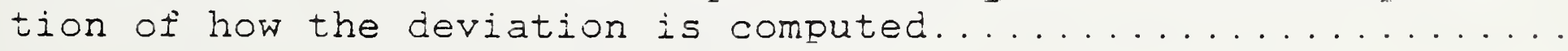





\title{
INTERLABORATORY COMPARISON OF \\ THE GUARDED HORIZONTAL PIPE-TEST APPARATUS
}

\author{
Precision of \\ ASTM Standard Test Method C 335 \\ Applied to Mineral-Fiber Pipe Insulation
}

David R. Smith

\section{NATIONAL INSTITUTE OF STANDARDS AND TECHNOLOGY BOULDER, COLORADO 80303-3328}

Apparent thermal conductivity of refractory pipe insulation from the same production lot was measured by seven different laboratories. The purpose of this intercomparison was to assess the precision and bias of the ASTM Test for Measurement of Steady-State Heat-Transfer Properties of Horizontal Pipe Insulation (C 335 ). Four laboratories submitted conductivity measurements for conditioned specimens. The test results for thermal conductivity of the four conditioned specimens include the temperature range from 318 to $652 \mathrm{~K}$ and illustrate the interlaboratory reproducibility as well as the temperature dependence of the conductivity. The standard deviation of the data from each participating laboratory was measured by their deviation from a polynomial function fitted to all data. For the 16 test results from the four laboratories that conditioned their specimens, the standard deviation was 4.3 percent. For all test results from all seven participants, the standard deviation was 5 percent. This value is offered as the estimated precision of the horizontal pipe-test method. The accuracy of this pipetest method cannot be estimated from the data obtained in this intercomparison.

Key words: accuracy; apparent thermal conductivity; bias; guarded hot plate; high temperature; horizontal pipe; insulation; interlaboratory comparison; mineral fiber; precision; standard test method.

This work was supported in part by Oak Ridge National Laboratory of the U.S. Department of Energy, through contract ORNL/IA-21428. 
A Iirm principle of measurement science is that a number for the magnitude of a physical property such as thermal conductivity conveys little information unless the precision and accuracy of the numerical value are also given. The wise user seeks to know the precision and accuracy of the value in order to understand the confidence that he or she legitimately can give to the information. Manufacturers of products such as thermal insulation, whose fitness for intended use depends on specific physical properties, are ethically and legally obligated to claim no more for the performance of their products than can be objectively demonstrated by accepted standard test methods. Thus manufacturers also need to know the precision and accuracy of numbers they want to use to represent the performance of their products. Then they can honestIy advertise all the benefits that their products are able to deliver to the consumer, without subjecting themselves to legal problems arising from misrepresentations.

Considerable progress has been made during the last twenty years in improving equipment and techniques described by standard ASTM test methods for measuring heat transfer in insulations, especially those used in the building industries, at temperatures near ambient. However there has been only limited knowledge available of the imprecision and bias of the ASTM test methods when they are extended to higher temperatures. During the last few years a concerted effort has been under way to evaluate the imprecision and bias of the various ASTM test methods for measuring heat transport through thermal insulations. The methods involving measurements at temperatures several hundred kelvins above room temperature are currently of particular interest.

Of the several instruments used to measure apparent thermal conductivity of insulation materials, two are important because they are independent of calibration materials and may be considered to embody "absolute" methods. These two instruments are the guarded hot plate (GHP), for specimens in the shape of flat slabs. and the horizontal pipe-test apparatus, for specimens in the shape of cylindrical shells. The laboratories of the U.S. National Institute of Standards and Technology, at Gaithersburg, Maryland (NIST-G), and at Boulder, Colorado (NIST-B), have played an active role in helping to improve equipment, focussing on guarded hot plates [14]. Apparent thermal conductivity of two matched specimens can be measured near room temperature with an accuracy of about 2 percent [5] in a guarded hot plate complying with ASTM Standard Test Method C 177 for "Steady-State Heat Flux Measurements and Thermal Transmission Properties by Means of the Guarded-Hot-Plate Apparatus" [6].

For measuring thermal conductivity of cylindrical pipe insulation the relevant ASTM test method is C 335, "Steady-State Heat Transfer Properties of Horizontal Pipe Insulation" [7], commonly referred to as the "horizontal pipe-test" (HPT) method. The imprecision and bias of this test method have not yet been established, and estimating these is the issue addressed by this report. 
As a consequence of the incomplete knowledge of the imprecision and bias of the UPT method over the higher range of temperatures typically used in practice, seven interested members of ASTM Subcommittee C-16.30 (Thermal Measurements) organized an interlaboratory comparison on this method in the fall of 1987. The objective was to measure specimens of homogeneous pipe insulation at mean temperatures between ambient and about $673 \mathrm{~K}(4000 \mathrm{C})$. Memiders of the task group wanted to move quickly to learn the present state of the quality of measurements with this method. To save time and to reduce damage to the specimen, they decided not to pass around the same specimen of pipe insulatior for measurement, but rather to measure concurrently specimens chosen from the same production lot. The deadine for completion of the measurements was chosen to permit results to be presented in the spring of 1988 at the ASTM C16.30 meeting in Atlanta, Georgia.

\section{COMPARISON OF THE GUARDED-HOT-PLATE AND PIPE-TEST METHODS}

The recent experience in determining the imprecision and the bias of the guarcied hot plate is relevant to efforts to determine them for the HPT method. The similarities and the differences between the two types of apparatus help us to understand the possibie causes of imprecision and bias in both instruments.

\section{a. The Guarded Hot Plate}

To assess the imprecision and bias of high-temperature GHPs. an interlaboratory comparison of measurements of apparent thermal conductivity was held in 1987 [8]. The study used GHPs designed for high temperature to measure fibrous alumina-silica and calcium silicate insulation boards as test specimens. This intercomparison showed that, for mean specimen temperatures ranging from 313 to 773 $K$, considerably larger uncertainties exist in measurements made with such GHPs than for room-temperature measurements. For the fibrous alumina-silica specimens the greatest deviations of the participants' data from a least-squares fitted curve were +20 and -12 percent, and the standard deviation was 7.4 percent. For calcium silicate specimens the greatest deviations of the participants' data from the fitted curve were +13 and -22 percent, and the standard deviation was 8.0 percent. Thus for the GHP considered as a standard ASTM instrument for measuring thermal conductivity at high temperatures, the standard deviation of its data from a fitted descriptor curve is almost 8 percent.

This was particularly surprising, because the GHP method is considered to be an "absolute" test method for determining thermal conductivity of insulations, because no calibration specimen is used with this apparatus. The conductivity of the specimens is simply calculated from several quantities obtained during the experiment and from the geometry of the specimen. 
The thermal conductivity of a specimen can be defined through Fourier's law as the ratio of heat Ilux, q. to the magnitude [dT/dX] of the thermal sradient (where square brackets denote the absolute value):

$$
k=q /[d T / d X]
$$

The heat flux $q$ is defined in terms of two physical quantities measured for the metered area of the source of heat. These quantities are the rate of transport $Q$ of thermal energy from the heater through the adjacent area of specimen, and the corresponding crosssectional area A through which the energy is conducted. The ratio of these, Q/A. defines the heat flux 7 through the meters area. Two other yirantitis cbtained during the course of the experiment are the temperature difference $\Delta T$ along the direction of heat flow, together with the correspording thickness of specimen $\Delta X$. However the ratio of these. $\Delta \mathrm{T} / \Delta \mathrm{X}$, only approximates the thermai frradient $d T / d X$ required by rouri. $r^{\prime} \equiv$ law. In practice, $k$ is defired by $a$ slight modification of relation (1), obtained by a single integration:

$$
\int_{1}^{2} k(T) d T=(Q / A) \cdot \Delta X
$$

where $\Delta X$ is the spatial separation between the surfaces at temperatures $\mathrm{T}_{1}$ and $\mathrm{T} 2$ bounding the specimen. Of course this relation (2) only implicitly specifies $k$.

The integral on the left side of this reiation may be replaced by an equivalent quantity, Lmean. (T2-T1). Alternatively, the GHP is often operated with temperature differences mail encugh that $h(T)$ may be estimatid by a constart, knean, over the applicable temperature interval. In either case, relation (2) takes a form which then explicitly defines the experimental thermal conductivity:

$$
\text { linean }=(Q / A) \cdot \Delta X /\left(T_{\hat{\imath}}-T_{1}\right) \text {. }
$$

The correctness of the GHP method is determined in practice by how nearly the apparatus approximates, within the metered area of the specimen, uniform and unidirectional flow of heat through an infinitely broad slab of material which has uniformly heated, parallel, planar surfaces and which is homogeneous along directions 
parallel to the surfaces.

The boundary temperatures at the surfaces of the specimens are maintained by heated (or cooled) plates whose temperatures are carefully controlled. If the specimens have a constant thermal conductivity (independent of temperature), the thermal gradient $\mathrm{dT} / \mathrm{dX}$ within the specimens is independent of position along the direction of heat flow in the test area, and then is exactly given by $\Delta T / \Delta X$. Any flow of heat into or out of the perimeter of the measured central area, or in other words, heat flow that has a component along the normal to the axis of symmetry within the metered area, leads to an erroneous value of thermal conductivity.

The existence of large differences among measurements carried out by different laboratories using the GHP method [8] indicates the possibility of uncompensated biases in measurement of the heat flux or of the thermal gradient. One possible source of bias is faulty thermal grounding, or tempering, of the leads of the thermocouples which measure the temperature difference from which the thermal gradient is calculated. Most GHP devices are 20 to $25 \mathrm{~cm}$ in diameter. with a consequent tempering path length of only 10 to $12 \mathrm{~cm}$ for the thermocouples measuring the thermal gradient at the center of the specimen. One exception is the NIST-G 1-meter GHP $[1,3]$, whose diameter leads to a greater length of tempering of the thermocouples used to measure the temperatures at the surfaces of the specimens. Other exceptions are the two (low-temperature and high-temperature) GHPs at NIST-B [2,4], which use extra tempering lugs to increase the effective length of thermal grounding of the thermocouple leads as they exit the GHF stack.

\section{b. The Horizontal Pipe-Test Apparatus}

Using the same criteria applied above to the GHP method, the ASTM C-335 HPT method for horizontal pipe insulation [7] could also be considered to be an absolute test method, although it is not at present so regarded. Like the guarded-hot-plate method, the C-335 HPT method is designed to simulate an ideal geometry of unidirectional heat flow. As with the GHP method, no calibration specimen is necessary with the HPT apparatus, and the conductivity is also calculated as the ratio of heat flux q to the (radial) thermal gradient, $d T / d r$, both being obtained in the course of the experiment.

One important operational difference between the two methods is that the GHP method uses relatively small temperature differences in measuring thermal conductivity, and uses an auxiliary heater to vary the mean temperature of the specimen independently of the magnitude of the temperature difference within it. In contrast, the HPT method relies on ambient (although controlled within $10 \mathrm{C})$ temperature to maintain the cold-side temperature of the specimen. It is not required that the HPT apparatus have an auxiliary heater with which to vary the mean temperature. It is permissible to vary the mean temperature by increasing the hot-side temperature, with a large difference of temperature within the specimen. 
With the HPT method, the cylindrical geometry of the physical apparatus used in this test method also complicates matters slight1y. The heat $f$ lux $q$ is the ratio of the rate heat of heat flow $Q$ to $a$ cylindrical area $2 \pi$ r located at the radial position $r$ measured from the central line heater and occupying an interval L along the axis of symmetry. The position $r$.is that at which the gradient, $d T / d r$. is evaluated. For this cylindrical geometry, Fourier's law takes the form.

$$
Q / 2 \pi r L=k \cdot d T / d r
$$

The presence of the $r$ factor in the left side makes the temperature gradient dT/dr a function of position $r$ even if $k$ is constant. This expression (4) must be integrated with respect to radial position to obtain a result applicable to the inite differences in $T$ and $r$ used in an actual experiment. This is easily done, and results in the expression

$$
(\mathrm{Q} / 2 \pi L) \ln \left(r_{2} / r_{1}\right)=\int_{1}^{2} k(\mathrm{~T}) \mathrm{dT},
$$

where $r 2$ and $r 1$ are the outer and inner radii of the cylindrical insulation specimen.

The factors $\mathrm{rl}$, $r 2$, and $L$ are constants during a given experiment. The integral of the thermal conductivity function between the temperatures $\mathrm{T} 1$ and $\mathrm{T} 2$ of the bounding surfaces is the conductivity-related quantity proportional to the heater power $Q$. It is the integral of thermal conductivity which is obtained from the conditions of the experiment (Q, $r 1, r 2$ and $L)$, rather than the thermal conductivity alone. This integral of $k(\mathrm{~T})$ over $\mathrm{T}$ is mathematically equivalent to a product of conductivity and temperature, and may be used to define a "mean" conductivity by

$$
\text { kmean }=\int_{1}^{2} k(T) d t /\left(T_{2}-T_{1}\right) \text {, }
$$

which is generally not the same as k(Tmean) [11]. 
The correctness of the HPT method is determined by how neariy the HPT apparatus approximates purely radial flow of heat. from $a$ uniform source of heat at the center of symmetry, through an infinitely long cylinder of material which has concentric cylindrical surfaces and which is homogeneous along directions parallel to the surfaces. The boundary temperature at the inner surface of the specimen is maintained by a cylindrical heated pipe, whose temperature is carefully controlled. However, in contrast to the case of the GHP, the temperature at the outer (cooler) surface of the insulation is not maintained by a temperature-controlled surface, but rather by the ambient, laboratory temperature. Even though the laboratory temperature may be controlled, the temperature of the specimen surface is not as tightly controlled as it would be by a cooled surface in thermal contact with it. Also, because of the cylindrical geometry, which causes the heat flux lines to diverge from the linear center of symmetry, the temperature gradient within the specimen must always be a function of position from the central heater, in contrast to the situation with the GHP method. This is true even if the conductivity is independent of position along the direction of heat flow.

Any flow of heat along the direction parallel to the cylindrical symmetry axis, into or out of the boundaries of the measurement length, or in other words, heat flow that has a component parallel to the axis of symmetry, would lead to an erroneous value of thermal conductivity. The temperatures defining the thermal gradient are measured by thermocouple leads introduced along a cylindrical isothermal surface. A greater length of thermal grounding of the leads, typically 30 to $45 \mathrm{~cm}$, is possible in comparison to the length available with the disk-shaped heater plates in the GHP. This is so because of the commonly encountered combined length (60 to $90 \mathrm{~cm}$ ) of the test and guard regions within the cylindrical HPT apparatus.

Only the GHP method has found wide acceptance in the U.S. as the prime method for measuring thermal conductivity of insulating materials. One major factor is that the GHP method uses specimens in the shape of flat slabs, which is the most common geometry for insulation materials. Although each GHP apparatus has a definite limit on the maximum thickness of specimen whose conductivity it can measure accurately, specimens of any thickness less than that maximum may be measured. The cylindrical geometry of the HPT method is on the other hand somewhat restrictive because a given apparatus can measure only specimens of radius matching that of the cylindrical inner surface, even though any size of outer surface may be used. Manufacture of homogeneous insulation specimens of cylindrical shape is somewhat more difficult than that of flat-slab specimens.

To date no systematic comparison has been carried out to link results on identical materials measured with both the guarded hot plate and the HPT methods. Such a comparison would be a valuable test of the accuracy and bias of both methods, in light of the existing uncertainty in measurements with high-temperature GHPs. 
One study by Kimball [9] of a large HFT apparatus compared calculated steady-state thermal conductance (rate of heat flow per unit area, per kelvin) with experimental measurements, for nominal 3-inch polyurethane foam insulation, used on 18-inch pipelines in the Arctic. He reported measuring conductance through the insulation with an exterior temperature of $-56.70 \mathrm{C}$ (-700F) and an interior (pipe) temperature of $+710 \mathrm{C}(+1600 \mathrm{~F})$. The experimental thermal conductance was 6 percent higher than the theoretical. This discrepancy was explained by heat leak from the interior along the central boundary joining the two abutting sections making up the complete specimen. A measurement of the conductance at $7.20 \mathrm{C}$ ( $450 \mathrm{~F})$ under transient conditions agreed within 4 percent with the corresponding calculated value.

The only previous interlaboratory comparison of the test method for horizontal pipe insulation took place over a period of more than seven years and was reported by Hollingsworth [10] in 1977. Ten laboratories took part in this comparison, which covered a range of mean specimen temperatures from about 323 to $423 \mathrm{~K}$; the highest pipe-heater temperature used was about 533 K (2600 C). Hollingsworth concluded that the test error was approximately 3 percent. However, both the HPT method and the insulations tested with it are frequently used at mean temperatures much higher than the upper limit of $423 \mathrm{~K}$ of the 1977 intercomparison.

\section{SCOPE}

This report analyzes apparent thermal conductivity of hightemperature pipe insulation measured by seven testing laboratories using guarded horizontal pipe-test apparatuses. Their instruments comply with ASTM test method C 335 for "Steady-State Heat Transfer Properties of Horizontal Pipe Insulation." The specimens measured were homogeneous mineral-fiber insulation designed for use at temperatures up to $600 \mathrm{~K}$ or more. Four of the testing laboratories submitted data for "conditioned" specimens, over the range of mean temperatures from 318 to $652 \mathrm{~K}$. The results presented here apply specifically only to homogeneous specimens, to measurements within the cited range of temperatures, and to guarded, horizontal pipetest apparatus. Extension of these results to inhomogeneous specimens, to calibrated rather than guarded apparatus, to vertically oriented apparatus, or to temperatures outside the cited range, is inappropriate.

Only one nominal density of pipe insulation was measured. Furthermore, visual inspection shows that the pipe insulation material has relatively large pores, with dimensions of up to tenths of a millimeter. Only for an insulation material for which all pores have dimensions of less than micrometers ("microporous") would pressure dependence be a factor in its thermal conductivity. This implies that intercomparisons of the thermal conductivity data reported here do not have to be corrected for the elevation above sea level of the different participating laboratories. 


\section{PARTICIPANTS AND APPARATUSES}

The chairman of the task group. who took part in the intercomparison, carefully selected some specimens from one supplier and distributed them to the other six participating laboratories. After the thermal conductivity was measured the seven participants submitted their data directly to me for analysis.

The names of the seven laboratories participating in the intercomparison are given here in alphabetic order to identify the sources of the data presented. Listing these names does not in any way imply endorsement of the organizations, or of their products or services. either by NIST in particular, or by the U.S. government. The seven participants were:

California Bureau of Home Furnishings and. Thermal. Insulation CertainTeed Corporation, Blue Bell, Pennsylvania

Dynatech Scientific, Inc. (now Holometrix): Cambridge, Mass.

Fiberglas Canada, Inc. Sarnia, Ontario. CANADA.

Manville Corporation, Denver, Colorado

Owens-Corning Fiberglas, Granville, Ohio

PABCO, Fruita, Colorado

Random numbers and symbols were assigned.to:the data sets from the participants and used throughout the figures.in, this report. The symbols chosen are listed in table. 1; along. with the characteristics of the horizontal HPT apparatus used by . the participants. All apparatuses were "guarded" rather than "calibrated" HPT apparatuses, and all had nominal diameters of. 3 .in (actual diameters. of $3.5 \mathrm{in}$, or $89 \mathrm{~mm}$ ).

Table 1. Coding symbols used in figures to distinguish the ------ seven laboratories participating in the interlaboratory comparison, and sizes of their nominally'3-inch pipe-test apparatus.

\begin{tabular}{|c|c|c|c|c|c|}
\hline $\begin{array}{l}\text { Lab } \\
\text { Code }\end{array}$ & $\begin{array}{c}\text { Lab } \\
\text { Symbol }\end{array}$ & $\begin{array}{l}\text { Metered } \\
(\mathrm{cm})\end{array}$ & $\begin{array}{l}\text { Length } \\
\text { (in) }\end{array}$ & $\begin{array}{l}\text { Guard } \\
\text { (cm) }\end{array}$ & $\begin{array}{c}\text { Length } \\
\text { (in) }\end{array}$ \\
\hline 1 & 0 & 91.4 & 36 & 30.5 & 12 \\
\hline 2 & $\Delta$ & 61.0 & 24 & 15.2 & 6 \\
\hline 3 & 口 & 91.4 & 36 & 30.5 & 12 \\
\hline 4 & $\nabla$ & 61.0 & 24 & 7.6 & 3 \\
\hline 5 & 0 & 91.4 & 36 & 30.5 & 12 \\
\hline 6 & + & 61.0 & 24 & 15.2 & 6 \\
\hline 7 & $x$ & 61.0 & 24 & 10.2 & 4 \\
\hline
\end{tabular}


When the test results were submitted and presented at the Atlanta metting of ASTM C 16.30 in the spring of 1988, it was realized from the order in which the data had been submitted that an important item had been overlooked. Five participants had measured the thermal conductivities of their specimens with mean temperature increasing trom one measurement to the next. However, the specimens may change slightly as the temperature increases during the sequence of measurements leading to the highest temperature of measurement. For example, some binder begins to burn out of the insulation when it is heated to temperatures above about $400 \mathrm{~K}$; other physical changes, such as loss of adsorbed water. followed at still higher temperatures by loss of water of crystallization, can take place to some degree, depending on the composition of the insulation material and on the highest temperature to which the specimen is subjected. Such changes, although minor in their overall effect, still lead to variation in the physical properties of the specimen under study. Except for loss of adsorbed moisture from the surfaces of the pores, these changes are irreversible and permanent. Each increase in mean temperature alters the specimen: therefore successive measurements on the "same" specimen are actually being performed on slightly different specimens.

On the other hand. we can hope that the specimens of insulation material as received from the manufacturer have already been uniformly conditioned by the manufacturing process. Thus even in the presence of physical changes caused by heating to the temperatures used in this study, all specimens have identical histories during comparative measurements of conductivity up to the lowest maximum temperature employed by the group of participants. If heating the specimens causes physical changes affecting the thermal conductivity, then only specimens heated to temperatures greater than the maximum of another participant are different from that participant's specimen. Of course, the specimen heated to the group's maximum of temperature becomes unique.

Even if we accept this view, after the maximum temperature is reached the properties of a particular specimen depend on what that maximum was; no further loss of binder or of water of crystallization should take place unless the maximum temperature is later exceeded. Measurements of conductivity thereafter should be reproducible, but they will be different from those initially obtained in the first excursion from low temperatures to the maximum. Thus we still conclude that, if we want to know what the conductivity of the material is, we should use only the data obtained after the specimen has reached its maximum temperature.

To obtain stable and reproducible results, specimens of hightemperature pipe insulation should first be conditioned, or stabilized, by heating to the highest temperature of measurement when this lies more than about $80 \mathrm{~K}$ above room temperature. Also, the conditioning temperature should be the same for all laboratories in 
the intercomparison.

Only then are the different specimens stable and suitable for use in an interlaboratory comparison. However one other difficulty is that not all laboratories could reach the same highest temperature, and the highest temperature that all could reach was not determined beiore the intercomparison began. For these reasons, EIight variations in the heat-transter properties of the material were unavoidable. These variations, which are actualIy material variability, may appear disguised as interlaboratory variation in the data submitted by the participants.

Five laboratories had measured thermal conductivity before stabilizing their specimens at the highest temperature. These participants agreed, as time allowed, to remeasure their specimens before the C-16.30 Tucson meeting in the fall of 1988. Two laboratories were able to submit data for their repeated measurements. All data submitted by the participants in the intercomparison are presented here for review. Because of differences in conditioning of the test specimens, several different points of view will be used to critically examine the conductivity measurements in order to estimate the imprecision and the bias of the horizontal pipetest method as present?y standardized by ASTM method C 335.

\section{THERMAL CONDUCTIVITY DATA}

The thermal conductivity data submitted by the participants on the standardized forms provided to them were compiled into tabular files for analysis by computer. One participant submitted data directly in SI units; the remaining data, submitted in engineering units, were converted to SI units for uniformity and ease of comparison.

Table 2 contains all the test data for the pipe insulation used in this intercomparison (in the column headed Kdat). In particular, in table 2 the first four lines of data for laboratories 2 and 4 , and $a i l$ the data for laboratories 3,5 and 7 are for nonconditioned specimens (data taken with temperature increased between measurements). Because the fourth. Iine of data for laboratory 4 is for the maximum temperature of measurement, it is effectively a conditioning point; thus the last line for laboratory 4 , and the fourth line, are for a conditioned specimen. All the data for laboratories 1 and 6 , and the last four lines of data for laboratory 2 are also for conditioned specimens. The complete data set is plotted in figure 1, with seven different symbols used to distinguish the data from the seven participants. As is conventional, the points are plotted in figure 1 at a value of temperature equal to the mean of the two boundary temperatures. However the experimental values of thermal conductivity (Kdat) are averages of the conductivity over the complete temperature interval and are therefore to be associated with that specific interval. 


\section{REFERENCE EQUATIONS AND DATA ANALYSIS}

It is now widely appreciated that several factors contribute to the total transfer of heat from one boundary surface to the other in most insulations. The main contritution is usually conductive, due to diffusive flow of heat driven by a temperature gradient, or spatial rate of change of temperature, through the solids and surrounding gas. However another important component is radiative heat transfer, for which the radiated energy flux per unit time is driven not by a spatial gradient but by the difference between the fourth powers of the temperatures at the bounding surfaces:

$$
q r a d=B \cdot\left(T H_{4}^{4}-T^{4}\right) \text {, }
$$

where $B$ is a combination of several constants. The quantity in parentheses can be algebraically factored into several terms, one of which is the difference ( $\mathrm{TH}-\mathrm{TC}$ ) between the boundary temperaures. Thus this relation can be cast into the form of Fourier's law of conduction involving the usual approximation $\Delta T / \Delta X$ to the temperature gradient: one then obtains an effective "radiative" conductivity. Equation (6) can be transformed into an algebraically identical form:

qraa $=\left[B \cdot\left(\mathrm{TH}^{2}+\mathrm{Tc}^{2}\right) \cdot\left(\mathrm{TH}+\mathrm{Tc}_{\mathrm{c}}\right) \cdot \Delta \mathrm{X}\right] \Delta \mathrm{T} / \Delta \mathrm{X}$,

where $\Delta T$ is the temperature difference ( $T H-T c$ ), and the quantity in square brackets is the "radiative" conductivity parameter, obtained at the cost of introducing into it a dependence on specimen thickness $\Delta X$. An additional result of interest is that this "radiative conductivity" varies approximately as Tmean ${ }^{3}$, where Tmean is the arithmetic mean of $\mathrm{TH}$ and $\mathrm{TC}$.

Fourier's law of conduction, which relates the conductive heat transfer to the thermal gradient, only approximately models the total heat transfer within an insulation. The total transfer of heat between two different isotherms within an insulation material depends partly on the difference of the temperatures if radiative transport of heat is appreciable. This radiative heat transfer term may be added to the conductive term under the (only approximately valid) assumption that they represent non-interactive and parallel, or linearly additive, modes of heat transfer. The resultant total heat transfer, which is predominantly, but not purely, conductive, is called the "apparent" thermal conductivity to distinguish it from a true conductivity driven only by a thermal gradient. For brevity, the term "thermal conductivity" will be used in the following text and figures. 
In the analyses below, the "thermal conductivity integral method $[11,12]$ was used in fitting thermal conductivity functions to experimental data. That is, a specific polynomial for the thermal conductivity as a function of temperature was assumed, and then integrated, and the polynomial function was fitted to the data by means of a least-squares fit to obtain the numerical values of the coefficients in the assumed relation. The deviations shown in the tables and in the deviation plots were also calculated by the integral method. This was done to remove any potential inconsistency caused by the presence of both large and small temperature differences in the data set. The use of large temperature differences is inherent in ASTM method C 335 for measurements of pipe insulation at mean temperatures well above room temperature.

When we fitted functional curves to the experimental conductivity data, weighted least-squares fits were used; the weighting was chosen to minimize the sum of the squares of the relative deviations, rather than the sum of squares of absolute deviations. This is considered preferable because when measuring thermal conductivity, experimentalists tend to keep the relative (percentage) errors constant.

The seven participants' complete set of data for the thermal conductivity of pipe insulation extends over the range of mean temperatures from 318 to $652 \mathrm{~K}$ (table 2). These data include measurements for both conditioned and nonconditioned specimens. The variation of conductivity with temperature for the complete data set can be represented by the correlation

$$
k=16.734+0.04180 \mathrm{~T}+0.17954 * 10-6 \mathrm{~T}^{3},
$$

where $k$ is in $\mathrm{mW} /(\mathrm{m} \cdot \mathrm{K})$ and $\mathrm{T}$ is in $\mathrm{K}$; this relation is plotted as the solid line in figure 1. The presence of the term in T3 represents an expected contribution from "radiative" conductivity. The coefficients in eq(9) were obtained from a weighted least-squares fit of the data, for specimens having a mean density of $91 \mathrm{~kg} / \mathrm{m}^{3}$. The standard deviation of density about the mean is 4.55 percent.

Because of the position of the solid line below the high-temperature data in figure 1, the curve appears to be an incorrect fit. This is however an artifact of experiments performed to measure thermal conductivity at large temperature differences of materials whose conductivity is a nonlinear function of temperature. This situation is normal in measurements with the HPT method, which uses very large temperature differences. Use of the "thermalconductivity integral" method reflects this state of affairs and correctly illustrates the relations between the individual data points and the thermal conductivity function. Here the functional 
curve is concave upward. As a consequence, any given data point, which is closely related to the integral of the conductivity function over the interval between the boundary temperatures, is displaced upward $[11,12]$.

The deviations of the individual data points from the curve representing eq(9) are plotted in figure 2 and listed in the last two columns of table 2 as absolute deviations (Dev) and as relative, or percentage, deviations (Kdev). Measurements on conditioned specimens by laboratories 2 and 4 (triangles) are indicated in figures 1 and 2 by the filled triangles, and repeated measurements by laboratory 6 (plus signs) are given by plus signs within circles. As discussed in references 11 and 12 , experimental data (Kdat) are actually averages of the thermal conductivity over the interval from $\mathrm{Tl}$ ow (or $\mathrm{T} 1$ ) to Thigh (T2). Numbers in the Kealc column of table 2 were obtained by the thermal-conductivity integral method, and represent likewise the temperature-averaged mean of the conductivity function, eq(9), over the interval from Trow to Thigh.

For the complete set of data the greatest positive deviation from the fitted curve is 8.3 percent, and the greatest negative deviation is -9.8 percent. The standard deviation of the measurements from the curve is 5.0 percent.

One participant questioned whether this method of fitting is fair, as three laboratories each submitted only four data points, while one submitted eight data points. In fact, the contribution from each participant is weighted by the number of data points taken. This has the consequence that the sets of data from laboratories 1, 3, and 5 are each given only $50 \%$ of the weight of the set from laboratory 6. All other laboratories (submitting four, five, or six data points) are also given only a fraction of the weight of the one providing eight points. In the matter of weighting data points equally as opposed to weighting laboratories equally, I agree that the point should be explicitly addressed, rather than defaulting to an unexamined assumption. Both ways were tried.

A new fit was performed over the same set of data, with weightings chosen to give each laboratory equal weight, based on "one man, one vote," rather than the choice of "one data point, one vote" that led to eq(9). The results of this fit yielded the correlation

$$
\mathrm{k}=18.184+0.036504 \mathrm{~T}+0.18478 * 10-6 \mathrm{~T}^{3}
$$

with $k$ and $T$ defined as before. This functional relation is plotted in figure 3. The deviations of the data points from this curve are plotted in figure 4 and listed in the last two columns of table 3. For this curve for equally weighted laboratories the 
greatest positive deviation of the defining set of data is +8.5 percent and the greatest negative deviation is -9.2 percent, compared to deviations of +8.3 and -9.8 percent from the curve given by eq(9) for equaliy weighted data. The standard deviation here is 5.1 percent, as opposed to 5.0 percent for the equally weighted data. Thus for both methods of weighting data, the results are closely similar: greatest deviations of about +8.5 and -9.5 percent, and a standard deviation of 5 percent.

To estimate the precision of measurements periormed by the HPT method, let us examine the set of data from only those participants that measured their specimens atter conditioning (heating the specimens first to the highest temperature of measurement and then performing measurements. These data are from participants identified by code numbers $1,2,4$ and 8 and are listed in table 4; the data are plotted in figure 5, encoded by symbols distinguishing the laboratories responsible for the data. The data from laboratory 2 are repeated measurements; data from laboratory 6 include both original data, which according to the submitted data sheet are valid, as well as additional data submitted in response to the call for repeated measurements. Laboratories 3,5 and 7 , which had not submitted data for conditioned specimens, were apparently not able to perform repeated measurments. Thus there were four laboratories providing data on conditioned specimens.

By means of a least-squares fit a correlation of the same form as that of eq(9) was obtained. This correlation for the data from conditioned specimens is given by

$$
\mathrm{k}=10.449+0.066314 \mathrm{~T}+0.140223 * 10-6 \mathrm{~T}^{3},
$$

with $\mathrm{k}$ and $\mathrm{T}$ defined as before. This correlation is plotted as the solid line in figure 5. The data used to obtain this correlation cover the range in temperature from 318 to $652 \mathrm{~K}$. Deviations of the individual data points from eq(10) are plotted in figure 6 and are listed in the last two columns of table 4.

The greatest positive and negative deviations of data points from the correlation (11) are both 6.4 percent; the total set of data fits the curve within a standard deviation of 4.3 percent. This standard deviation is considerably smaller than the standard deviation of the results from the interlaboratory comparison for the high-temperature GHPs [8], which covered a slightly greater temperature range $(297$ to $773 \mathrm{~K})$, including the range used in this study. This comparison yielded standard deviations of 7.4 and 8 percent for the two materials studied, and maximum deviations of almost \pm 20 percent. Although we must not push the comparison between the GHP and the HPT methods too far, as there were only 
seven participants in each of the two interibboratory comparisons. comparisons between the precisions ot the two methoda might be made cautiousiy.

Having iitted only the data for conditicned specimens, obtaining eqi11), we now fit the set af data for nonconditioned jpecimens and compare the tio sets. Mable 5 lists the data for these nonconditioned specimens, which are plotted in figure 7 . A weighted least-squares itt to the data for nonconditioned specimens gave the correlation

$$
\mathrm{k}=42.980-0.05409 \mathrm{~T}+0.34209 * 10^{-6} \mathrm{~T}^{3},
$$

with $k$ and $T$ defined as before. This correlation is plotted as the solid line in figure 7.

The last two columns of table 5 show the deviations from the least-squares fit to these data, and the relative deviations are plotted in figure 8. The point of interest is that these data for nonconditioned specimens exhibit extremal deviations from the fitted curve of +6.9 and -7.5 percent. This is somewhat larger that the corresponding deviations of data for conditioned specimens from their fitted curve, as would be expected if the effect of conditioning is real. The standard deviation from the fitted curve for nonconditioned specimens is 4.7 percent, as opposed to 4.3 percent for the conditioned specimens.

The internal self-consistency of data for conditioned specimens seems to be better than that for nonconditioned specimens. We might conclude that conditioning makes a difference, but with reservations--there are only four sets of data for conditioned specimens and only five sets for nonconditioned specimens. The sizes of the two statistical samples are too small for us to be sure that the effect of conditioning is real.

The standard deviation of the complete set of thermal conductivity data, including measurements on both conditioned and nonconditioned specimens, is about 5 percent. The precision of the HPT method was estimated to be about 4.3 percent, so the effect of not conditioning the specimens seems to be about 1 percent.

Another instructive exercise is to compare the data for the nonconditioned specimens with the fitted curve for conditioned specimens; this curve is given analytically by eq (11). This was done by preserving the shape of the curve for conditioned specimens and simply raising it up or down parallel to the conductivity axis. 
That is, we found a constant multiplier equal to 0.98, such that the rms deviations from this curve were minimized for data for nonconditioned specimens. The least-squares fit for this procedure is shown by the solid curve in figure 9 and the deviations are plotted in figure 10. The numerical values for this fit are given in table 6. The extremal deviations of the data for nonconditioned specimens were \pm 9.7 percent, and the standard deviation of the fit is 5.4 percent.

This situation for a subset of the data appears paradoxical at first, with a standard deviation of 5.4 percent for the subset of nonconditioned specimens, compared with a standard deviation of only 4.95 for the set of all data, from the curve described by eq(9). This standard deviation of 5.4 percent may be understood to measure the internal consistency of data for purely nonconditioned specimens. The internal consistency of data for conditioned specimens, the complementary subset of data, is measured by a standard deviation of only 4.3 percent, which is less than the standard deviation of 4.95 for the complete set. The standard deviation for conditioned specimens is about 1 percent greater than that for nonconditioned specimens. Remembering that we deal here with a small statistical sample, we may again cautiously conclude that conditioning may make a difference of about 1 percent.

\section{ESTIMATED PRECISION OF THE HPT METHOD}

In measurement theory imprecision in a series of measurements of a physical quantity indicates the closeness of approach of the individual values to the mean value. Precision says nothing about how the mean value compares to the "true" value. Scatter of the measurements around the mean value is caused by random influences, which by definition have unpredictable magnitude and sign, and will tend to cancel out each other if a large enough number of measurements is made. The mean value of a large enough group of measurements of the same physical quantity tends to become free of the etfects of the random influences.

By contrast, accuracy of a physical quantity indicates the closeness of approach of the mean of a series of measurements to the "true" value. Inaccuracy is caused by nonrandom, or systematic errors of measurement, which have not been corrected during the process of measurement because they are not known to the person performing the processes of measurement and analysis. These systematic errors, if present, might be disclosed by performing measurements of the same physical quantity on the same material but in a different type of apparatus, preferably based on a different principle of measurement. One could postulate that the true value is reached in the limit of a very large number of measurements, performed under very different conditions. If a large enough population of measurements has been obtained from many different types of apparatus that measure the same quantity, such that errors made in measurements based on one type of apparatus are offset by errors 
in measurements from very different apparatuses, then the mean value of this large set of measurements may approach the "true" value. Accuracy of a set of measurements performed on one apparatus is then indicated by the difference between the mean value for the apparatus and the global mean for all apparatuses, that estimates the true value.

The present interlaboratory comparison of the-HPT method involves instruments of the same type, so there may be inherent in this method some biases that have not been revealed by these measurements. We do not know of any comparative measurements of the same pipe insulation material on an apparatus of a different type. For the HPT method there is neither a theoretical value nor a standard reference material against which to compare the experimental results. Therefore the "true" value of the material measured here is unknown. An estimate of accuracy of the horizontal pipe-test method cannot be made at this time.

The precision of measurements with the HPT method is indicated by the scatter of measurement data around the group mean. One estimate of the group mean of the thermal conductivity is given by the fitted curve, eq (11), for conditioned specimens measured by four different laboratories. An estimate of the scatter of the data around the mean for the four laboratories is given by the standard deviation of the data ( 4.3 percent) from the fitted curve. A larger statistical sample for basing an estimate of accuracy is available: the complete set of data including both conditioned and nonconditioned specimens. For this set the standard deviation, or scatter of data about the mean, is about 5 percent. Preferring to be conservative by basing the estimate on the largest possible set of data and by choosing the looser of the two possible estimates, I estimate the precision of the HPT method to be 5 percent over the range of temperature from 318 to $530 \mathrm{~K}$. This is based on measurements performed with only one type of apparatus, the guarded-end HPT apparatus, and only one type of insulation material. Caution should be exercised in generalizing these results to another type of HPT apparatus.

Because the participants in this interlaboratory comparison did not measure the same specimen, but rather measured different specimens (obtained from the same supplier, to reduce variability), some of the scatter of the measurements about the mean, or imprecision, may be due to material variability in the heat-transfer properties of the different specimens used. 


\section{SUMMARY AND CONCLUSIONS}

Measurements of thermal conductivity have been presented for a mineral-fiber pipe insulation material at mean temperatures from 318 to $652 \mathrm{~K}$. Two methods of fitting the data were used: weighting individual data points equally, and weighting individual laboratories equally. There seems to be no significant difference in the closeness of the fits for the two different methods of weighting.

Of seven participating laboratories, four responded with data on specimens that were conditioned by heat first to the highest temperature of measurement, so that physical changes in the specimen had already occurred before data was taken. This conditioning was an issue that led to submission of additional measurements by the participants. Results from these laboratories, compared with measurements from those that did not do so, have suggested that conditioning the specimens before performing measurements may have a detectable effect on the measured thermal conductivity. The small number of participants makes it statistically difficult to draw firm conclusions on this point.

Reference equations are obtained which describe the dependence of the thermal conductivity on temperature for the refractory pipe insulation material, and are illustrated in the figures. Figures 1 and 2 compare results from all seven participants. Figures 3 and 4 make a similar comparison, with equal weighting for each participant. Figures 5 and 6 give the thermal conductivity of conditioned specimens. Figures 7 through 10 allow comparisons to be made with specimens that were not so conditioned. AlI the odd-numbered figures illustrate the fact that data points from measurements of thermal conductivity with large temperature differences do not coincide with the thermal conductivity function at the same temperature. This shows the necessity of using the thermal conductivity integral method $[11,12]$ to obtain the heat transport to be expected under large differences in temperature between boundaries.

The reference equations are used to analyze the precision of interlaboratory measurements made by the seven laboratories that participated in the round robin. The precision of measurement of thermal conductivity by the horizontal pipe-test method is estimated to be about 5 percent as measured by the standard deviation of measurements about the group mean for the participants. This estimate is almost independent of the effects of conditioning. An estimate of the accuracy of measurements performed with the HPT apparatus cannot be made at this time. 
The comparison of the guarded-hot-plate method with the pipetest method in Section 2 of this report suggest qualitatively that there may be fewer uncorrected biases in measurements made with the HPT apparatus than with the GHP at high temperatures. In contrast to the comparative method, which intrinsically depends on one or two reference materials in order to determine the conductivity of the specimen under study, both the HPT and the GHP involve "absolute" methods of measurement that are in principle independent of calibration standards. This interlaboratory comparison of the HPT method demonstrated that for a population of seven laboratories using both conditioned and nonconditioned specimens, the standard deviation of the data from the group mean was about 4.5 percent over a range of mean specimen temperatures up to $652 \mathrm{~K}$. Using only conditioned specimens over the same range of mean temperatures, four participants achieved a standard deviation from the group mean of only 4.3 percent. This is significantly better than the standard deviation of almost 8 percent resulting for the interlaboratory comparison of the GHP method at high temperatures. Although there is at present no standard reference material for cross-checking measurements made with the HPT apparatus, current evidence suggest that results of measurements with the HPT are on the average at least as good as those made with the GHP, both apparatuses being in principle "absolute" methods. With both instruments, care in experimental design and technique is indispensable in obtaining trustworthy data.

A very desirable next step would be to perform an interlaboratory test comparing the horizontal pipe-test apparatus and the guarded hot plate, on the same specimens. Because of the great difference in geometry inherent in these two measurement methods, it would be almost impossible to use identical specimens on the two different types of apparatus. However the use of loose-fill insulation materials, properly conditioned by standardized procedures, could permit the comparison of results from these two different types of apparatus. To compare measurements from these apparatuses is highly desirable, since the GHP apparatus when used at temperatures significantly higher than ambient seems to fall short of expectations. The limited information from two interlaboratory comparisons, each involving only seven laboratories, suggests that the HPT apparatus is more reliable at high temperatures than is the GHP. Yet the HPT method is limited to materials with cylindrical geometry, and cannot be used to measure a large fraction of the types of commercial insulation materials, in flat or block geometry, of great economic importance in residential building construction. 
[1]. Siu, M.C.I. and Bulik, C. "National Bureau of Standards Line-Heat-Source Guarded-Hot-Plate Apparatus", Rev. Sci. Instrum. $52 / 11,1709-1716$ (1981).

[2]. Smith, David R., Hust, J.G. and Van Poolen, Lambert J. "A Guarded-Hot-Flate Apparatus for Measuring Effective Thermal Conductivity of Insulations Between $80 \mathrm{~K}$ and $360 \mathrm{~K}$ ". NBSIR $81-1657$ (U.S. National Bureau of Standards, January 1982 ).

[3]. Rennex. Brian. "Error Analysis for the National Bureau of Standards $1016 \mathrm{~mm}$ Guarded Hot Plate", NBSIR 83-2674 (U.S. National Bureau of Standards, February 1983).

[4]. Hust, J.G., Filla, B.J., Hurley, J.A. and Smith, D.R. "An Automated High-Temperature Guarded-Hot-Plate Apparatus for Measuring Apparent Thermal Conductivity", NBSIR 88-3089 (U.S. National Bureau of Standards, May 1988).

[5]. Hust, J. G. and Pelanne, C. M. "Round Robins on the Apparent Thermal Conductivity of Low-Density Glass Fiber Insulations Using Guarded Hot Plate and Heat Flow Meter Apparatus". NBSIR 85-3026 (U.S. National Dureau of Standards, 1385 )

[6]. ASTM Standard Test Method C 177 for "STEADY-STATE HEAT FLUX MEASUREMENTS AND THERMAL TRANSMISSION PROPERTIES BY MEANS OF THE GUARDED-HOT-PLATE APPARATUS", ANNUAL BOOK OF ASTM" STANDARDS, Vol. 04.06, pp. 21-36 (ASTM, Philadelphia, 1986).

[7]. ASTM Standard Test Method C 335 for "STEADY-STATE HEAT TRANSFER PROPERTIES OF HORIZONTAL PIPE INSULATION", ANNUAL BOOK OF ASTM STANDARDS, Vol. 04.06, pp. 83-96 (ASTM, Philadelphia, 1986).

[8]. Kimball, L.R. "Thermal Conductance of Pipe Insulation--A Large-Scale Test Apparatus", Heat Transmission Measurements in Thermal Insulations, ASTM STP 544, pp. 135-146, (ASTM, Philadelphia, 1974).

[9]. Hollingsworth, M. Jr. "An Interlaboratory Comparison of the ASTM C 335 Pipe Insulation Test", Thermal Transmission Measurements of Insulation, ASTM STP 660, R.P. Tye, Ed.. pp. 50-59, (ASTM, Philadelphia, 1978).

[10]. Hust, Jerome G. and Smith, David R. "Round-Robin Measurements of the Apparent Thermal Conductivity of Two Refractory Insulation Materials, Using High-Temperature Guarded-Hot-Plate Apparatus", NBSIR 88-3087 (U.S. National Bureau of Standards, April 1988). 
[11]. Hust, J. G. and Lankford, A. B. "Comments on the Measurement of Thermal Conductivity and Presentation of a Thermal Conductivity Integral Method", International Journal of Thermophysics, 3/1, 6777, (1982).

[12]. ASTM Standard Test Method C 1045 for "CALCULATING THERMAL
TRANSMISSION PROPERTIES FROM STEADY-STATE HEAT FLUX MEASUREMENTS", ANNUAL BOOK OF ASTM STANDARDS, Vol. 04.06, pp. 689-696 (ASTM, Philadelphia, 1986 ). 
Toble 2. Interlaboratory comparison of apparent thermal conductivity of high-temperature mineral-fiber pipe insulation measured on seven different horizontal pipe-test apparatuses. The nominal density of the specimens is $90 \mathrm{~kg} / \mathrm{m}^{3}\left(5.6 \mathrm{lb} / \mathrm{ft}^{3}\right.$. Specimens had a nominal inner diameter of $89 \mathrm{~mm}$ ( $3.5 \mathrm{in})$. and a wall thickness of $51 \mathrm{~mm}$ ( $2 \mathrm{in}$ ). Measurements were performed at the ambient atmospheric pressure of each laboratory. 83 to 100 $\mathrm{kPa}$ (630 to 760 Torr). and at mean temperatures from 318 to $652 \mathrm{~K}$ (113 to $1238^{\circ} \mathrm{F}$ ). Kcalc is computed from eq (9). The standard deviation of the data set from eq (9) for all specimens is 4.95 percent.

\begin{tabular}{|c|c|c|c|c|c|c|c|c|c|}
\hline $\begin{array}{l}\text { Lab } \\
\text { No. }\end{array}$ & $\begin{array}{l}\text { Density } \\
\left(\mathrm{kg} / \mathrm{m}^{3}\right)\end{array}$ & $\begin{array}{l}\text { Thigh } \\
\text { (C) }\end{array}$ & $\begin{array}{l}\text { TI ow } \\
\text { (C) }\end{array}$ & $\begin{array}{r}D \in I T \\
(C)\end{array}$ & $\begin{array}{r}\text { Tove } \\
\text { (C) }\end{array}$ & $\begin{array}{c}\text { Kcalc } \\
m w /(m \cdot K)\end{array}$ & $\begin{array}{c}\text { Kdat } \\
m w /(m \cdot K)\end{array}$ & Dev & $\begin{array}{l}\text { Kdev } \\
\text { (Pct) }\end{array}$ \\
\hline 1 & 100.91 & 942.928 & 360.983 & 581.944 & 651.956 & 103.649 & 100.294 & -3.36 & -3.24 \\
\hline 1 & 100.91 & 854.483 & 349.039 & 505.444 & 601.761 & 87.912 & 84.010 & -3.90 & -4.44 \\
\hline 1 & 100.91 & 687.094 & 328.261 & 358.833 & 507.678 & 64.382 & 62.828 & -1.55 & -2.41 \\
\hline 1 & 100.91 & 503.706 & 309.650 & 194.056 & 406.678 & 46.497 & 45.536 & -0.96 & -2.07 \\
\hline 2 & 86.98 & 379.261 & 302.150 & 77.111 & 340.706 & 38.167 & 38.907 & 0.74 & 1.94 \\
\hline 2 & 86.98 & 419.206 & 306.150 & 113.056 & 362.678 & 40.667 & 40.924 & 0.26 & 0.63 \\
\hline 2 & 86.98 & 523.706 & 313.817 & 209.889 & 418.761 & 48.251 & 49.426 & 1.18 & 2.44 \\
\hline 2 & 86.98 & 632.928 & 323.928 & 309.000 & 478.428 & 58.444 & 61.531 & 3.89 & 5.28 \\
\hline 2 & 85.60 & 624.706 & 321.706 & 303.000 & 473.206 & 57.489 & 61.819 & 4.33 & 7.53 \\
\hline 2 & 85.60 & 526.094 & 310.983 & 215.111 & 418.539 & 48.262 & 51.156 & 2.89 & 6.00 \\
\hline 2 & 85.60 & 422.706 & 304.817 & 117.889 & 363.761 & 40.808 & 42.510 & 1.70 & 4.17 \\
\hline 2 & 85.60 & 379.372 & 302.428 & 76.944 & 340.900 & 38.187 & 39.483 & 1.30 & 3.39 \\
\hline 3 & 94.35 & 339.261 & 299.039 & 40.222 & 319.150 & & 38.907 & 2.97 & 8.27 \\
\hline 3 & 94.35 & 451.483 & 306.483 & 145.000 & 378.983 & 42.706 & 44.671 & 1.96 & 4.60 \\
\hline 3 & 94.35 & 590.928 & 318.706 & 272.222 & 454.817 & 54.150 & 56.199 & 2.05 & 3.78 \\
\hline 3 & 94.35 & 728.150 & 334.817 & 393.333 & 531.483 & 69.596 & 73.491 & 3.90 & 5.60 \\
\hline 4 & 92.26 & 439.706 & 303.761 & 135.944 & 37.1 .733 & 41.804 & 40.492 & -1.31 & -3.14 \\
\hline 4 & 92.26 & 529.761 & 311.039 & 218.722 & 420.400 & 48.550 & 47.553 & -1.00 & -2.05 \\
\hline 4 & 92.26 & 628.483 & 320.650 & 307.833 & 474.567 & 57.779 & 57.496 & -0.28 & -0.49 \\
\hline 4 & 92.26 & 726.539 & 332.928 & 393.611 & 529.733 & 69.250 & 68.303 & -0.95 & -1.37 \\
\hline 4 & 92.26 & 493.039 & 308.428 & 184.611 & 400.733 & 45.652 & 44.527 & -1.12 & -2.46 \\
\hline 5 & & 404.283 & 297.822 & 106.461 & & 39.354 & & & -7.00 \\
\hline 5 & 90.13 & 429.311 & 302.256 & 127.056 & 365.783 & 41.076 & 37.466 & -3.61 & -8.79 \\
\hline 5 & 90.13 & 502.089 & 306.483 & 195.606 & 404.286 & & 41.645 & -4.55 & -9.84 \\
\hline 5 & 90.13 & 551.383 & 312.694 & 238.689 & 432.039 & 50.377 & 45.680 & -4.70 & -9.32 \\
\hline 6 & & 549.561 & 310.639 & 238.922 & 430.100 & 50.099 & 50.147 & 0.05 & 0.10 \\
\hline 6 & 90.50 & 438.889 & 303.800 & 135.089 & 371.344 & 41.754 & 39.772 & -1.98 & -4.75 \\
\hline 6 & 90.50 & 348.761 & 298.617 & 50.144 & 323.689 & 36.390 & 35.305 & -1.09 & -2.98 \\
\hline 6 & 88.23 & 727.850 & 329.840 & 398.010 & 528.845 & 69.156 & 73.549 & 4.39 & 6.35 \\
\hline 6 & 88.23 & 533.100 & 309.600 & 223.500 & 421.350 & 48.722 & 52.193 & 3.47 & 7.12 \\
\hline 6 & 88.23 & 338.580 & 296.950 & 41.630 & 317.765 & 35.802 & 38.345 & 2.54 & 7.10 \\
\hline 7 & 90.50 & 375.650 & 300.261 & 75.389 & 337.956 & 37.877 & 38.042 & 0.17 & 0.44 \\
\hline 7 & 90.50 & 438.761 & 303.872 & 134.889 & 371.317 & 41.750 & 41.933 & 0.18 & 0.44 \\
\hline 7 & 90.50 & 493.539 & 308.428 & 185.111 & 400.983 & 45.688 & 46.256 & 0.57 & 1.24 \\
\hline 7 & 90.50 & 559.761 & 314.428 & 245.333 & 437.094 & 51.179 & 52.308 & 1.13 & 2.21 \\
\hline 7 & 90.50 & 679.150 & 327.150 & 352.000 & 503.150 & 63.434 & 65.421 & 1.99 & 3.13 \\
\hline
\end{tabular}


Tobl- 3. Interlaboratory comparison of apparent thermal conductivity of high-temperature mineral-fiber pipe insulation measured on seven different horizontal pipe-test apparatuses. Kcalc is computed from eq (10). obtained by weighting each laboratory equally. The standard deviotion of the data set from eq (10) for all specimens is 5.08 percent.

\begin{tabular}{|c|c|c|c|c|c|c|c|c|c|}
\hline $\begin{array}{l}\text { Lab } \\
\text { No. }\end{array}$ & $\begin{array}{l}\text { Density } \\
\left(\mathrm{kg} / \mathrm{m}^{3}\right)\end{array}$ & $\begin{array}{l}\text { Thigh } \\
\text { (C) }\end{array}$ & $\begin{array}{l}\text { TIow } \\
\text { (C) }\end{array}$ & $\begin{array}{r}D, 1 T \\
(C)\end{array}$ & $\begin{array}{l}\text { Tove } \\
\text { (C) }\end{array}$ & $\begin{array}{c}\mathrm{Kcol} c \\
\mathrm{mw} /(\mathrm{m} \cdot \mathrm{K})\end{array}$ & $\begin{array}{c}\text { Kdat } \\
m W /(m \cdot K)\end{array}$ & Dev & $\begin{array}{r}\text { Kdev } \\
\text { (Pct) }\end{array}$ \\
\hline 1 & 100.91 & 942.928 & 360.983 & 581.944 & 651.956 & 103.387 & 100.294 & -3.09 & -2.99 \\
\hline 1 & 100.91 & 854.483 & 349.039 & 505.444 & 601.761 & 87.518 & 84.010 & -3.51 & -4.01 \\
\hline 1 & 100.91 & 687.094 & 328.261 & 358.833 & 507.678 & 63.914 & 62.828 & -1.09 & -1.70 \\
\hline 1 & 100.91 & 503.706 & 309.650 & 194.056 & 406.678 & 46.165 & 45.536 & -0.63 & -1.36 \\
\hline 2 & 86.98 & 379.261 & 302.150 & 77.111 & 340.706 & 38.023 & 38.907 & 0.88 & 2.33 \\
\hline 2 & 86.98 & 419.206 & 306.150 & 113.056 & 362.678 & 40.452 & 40.924 & 0.47 & 1.17 \\
\hline 2 & 86.98 & 523.706 & 313.817 & 209.889 & 418.761 & 47.892 & 49.426 & 1.53 & 3.20 \\
\hline 2 & 86.98 & 632.928 & 323.928 & 309.000 & 478.428 & 57.994 & 61.531 & 3.54 & 6.10 \\
\hline 2 & 85.60 & 624.706 & 321.706 & 303.000 & 473.206 & 57.045 & 61.819 & 4.77 & 8.37 \\
\hline 2 & 85.60 & 526.094 & 310.983 & 215.111 & 418.539 & 47.905 & 51.156 & 3.25 & 6.79 \\
\hline 2 & 85.60 & 422.706 & 304.817 & 117.889 & 363.761 & 40.590 & 42.510 & 1.92 & 4.73 \\
\hline 2 & 85.60 & 379.372 & 302.428 & 76.944 & 340.900 & 38.042 & 39.483 & 1.44 & 3.79 \\
\hline 3 & 94.35 & 339.261 & 299.039 & 40.222 & 319.150 & 35.865 & 38.907 & 3.04 & 8.48 \\
\hline 3 & 94.35 & 451.483 & 306.483 & 145.000 & 378.983 & 42.445 & 44.671 & 2.23 & 5.25 \\
\hline 3 & 94.35 & 590.928 & 318.706 & 272.222 & 454.817 & 53.728 & 56.199 & 2.47 & 4.60 \\
\hline 3 & 94.35 & 728.150 & 334.817 & 393.333 & 531.483 & 69.125 & 73.491 & 4.37 & 6.32 \\
\hline 4 & 92.26 & 439.706 & 303.761 & 135.944 & 371.733 & 41.563 & 40.492 & -1.07 & -2.58 \\
\hline 4 & 92.26 & 529.761 & 311.039 & 218.722 & 420.400 & 48.189 & 47.553 & -0.64 & -1.32 \\
\hline 4 & 92.26 & 628.483 & 320.650 & 307.833 & 474.567 & 57.334 & 57.496 & 0.16 & 0.28 \\
\hline 4 & 92.26 & 726.539 & 332.928 & 393.611 & 529.733 & 68.781 & 68.303 & -0.48 & -0.69 \\
\hline 4 & 92.26 & 493.039 & 308.428 & 184.611 & 400.733 & 45.334 & 44.527 & -0.81 & -1.78 \\
\hline 5 & 90.13 & 404.283 & 297.822 & 106.461 & 351.053 & 39.177 & 36.601 & -2.58 & -6.57 \\
\hline 5 & 90.13 & 429.311 & 302.256 & 127.056 & 365.783 & 40.853 & 37.466 & -3.39 & -8.29 \\
\hline 5 & 90.13 & 502.089 & 306.483 & 195.606 & 404.286 & 45.867 & 41.645 & -4.22 & -9.20 \\
\hline 5 & 90.13 & 551.383 & 312.694 & 238.689 & 432.039 & 49.994 & 45.680 & -4.31 & -8.63 \\
\hline 6 & 90.50 & 549.561 & 310.639 & 238.922 & 430.100 & 49.720 & 50.147 & 0.43 & 0.86 \\
\hline 6 & 90.50 & 438.889 & 303.800 & 135.089 & 371.344 & 41.515 & 39.772 & -1.74 & -4.20 \\
\hline 6 & 90.50 & 348.761 & 298.617 & 50.144 & 323.689 & 36.304 & 35.305 & -1.00 & -2.75 \\
\hline 6 & 88.22 & 727.850 & 329.840 & 398.010 & 528.845 & 68.689 & 73.560 & 4.87 & 7.09 \\
\hline 6 & 88.22 & 533.100 & 309.600 & 223.500 & 421.350 & 48.360 & 52.210 & 3.85 & 7.96 \\
\hline 6 & 88.22 & 338.580 & 296.950 & 41.630 & 317.765 & 35.738 & 38.360 & 2.62 & 7.34 \\
\hline 7 & 90.50 & 375.650 & 300.261 & 75.389 & 337.956 & 37.742 & 38.042 & 0.30 & 0.80 \\
\hline 7 & 90.50 & 438.761 & 303.872 & 134.889 & 371.317 & 41.511 & 41.933 & 0.42 & 1.02 \\
\hline 7 & 90.50 & 493.539 & 308.428 & 185.191 & 400.983 & 45.370 & 46.256 & 0.89 & 1.95 \\
\hline 7 & 90.50 & 559.761 & 314.428 & 245.333 & 437.094 & 50.786 & 52.308 & 1.52 & 3.00 \\
\hline 7 & 90.50 & 679.150 & 327.150 & 352.000 & 503.150 & 62.968 & 65.421 & 2.45 & 3.90 \\
\hline
\end{tabular}


Table 4. Interlaboratory comparison of apparent thermal conductivity of high-temperature mineral-fiber pipe insulation. This set of specimens is restricted to only those which were conditioned by heating them to the highest temperature of measurement before data was taken. Kcalc is com puted from eq (11). The standard deviation of the data set from eq (11) for conditioned specimens is 4.34 percent.

\begin{tabular}{|c|c|c|c|c|c|c|c|c|c|}
\hline $\begin{array}{l}\text { Lab } \\
\text { No. }\end{array}$ & $\begin{array}{l}\text { Density } \\
\left(\mathrm{kg} / \mathrm{m}^{3}\right)\end{array}$ & $\begin{array}{l}\text { Thigh } \\
\text { (C) }\end{array}$ & $\begin{array}{l}\text { Tlow } \\
\text { (C) }\end{array}$ & $\begin{array}{r}\text { De IT } \\
\text { (C) }\end{array}$ & $\begin{array}{l}\text { Tave } \\
\text { (C) }\end{array}$ & $\begin{array}{c}\mathrm{Kca} \mid \mathrm{c} \\
\mathrm{mW} /(\mathrm{m} \cdot \mathrm{K})\end{array}$ & $\begin{array}{c}\text { Kdat } \\
m W /(m \cdot K)\end{array}$ & Der & $\begin{array}{l}\text { Kdev } \\
\text { (Pct) }\end{array}$ \\
\hline 1 & 100.91 & 942.928 & 360.983 & 581.944 & 651.956 & 100.280 & 100.294 & 0.01 & 0.01 \\
\hline 1 & 100.91 & 854.483 & 349.039 & 505.444 & 601.761 & 86.299 & 84.010 & -2.29 & -2.65 \\
\hline 1 & 100.91 & 687.094 & 328.261 & 358.833 & 507.678 & 64.754 & 62.828 & -1.93 & -2.98 \\
\hline 1 & 100.91 & 503.706 & 309.650 & 194.056 & 406.678 & 47.386 & 45.536 & -1.85 & -3.90 \\
\hline 2 & 85.60 & 624.706 & 321.706 & 303.000 & 473.206 & 58.210 & 61.819 & 3.61 & 6.20 \\
\hline 2 & 85.60 & 526.094 & 310.983 & 215.111 & 418.539 & 49.164 & 51.156 & 1.99 & 4.05 \\
\hline 2 & 85.60 & 422.706 & 304.817 & 117.889 & 363.761 & 41.498 & 42.510 & 1.01 & 2.44 \\
\hline 2 & 85.60 & 379.372 & 302.428 & 76.944 & 340.900 & 38.681 & 39.483 & 0.80 & 2.07 \\
\hline 4 & 92.26 & 726.539 & 332.928 & 393.611 & 529.733 & 69.299 & 68.303 & -1.00 & -1.44 \\
\hline 4 & 92.26 & 493.039 & 308.428 & 184.611 & 400.733 & 46.526 & 44.527 & -2.00 & -4.30 \\
\hline 6 & 90.50 & 549.561 & 310.639 & 238.922 & 430.100 & 50.988 & 50.147 & -0.84 & -1.65 \\
\hline 6 & 90.50 & 438.889 & 303.800 & 135.089 & 371.344 & 42.492 & 39.772 & -2.72 & $-6.4 \theta$ \\
\hline 6 & 90.50 & 348.761 & 298.617 & 50.144 & 323.689 & 36.698 & 35.305 & -1.39 & -3.80 \\
\hline 6 & 88.23 & 727.850 & 329.840 & 398.010 & 528.845 & 69.195 & 73.549 & 4.35 & 6.29 \\
\hline 6 & 88.23 & 533.100 & 309.600 & 223.500 & 421.350 & 49.618 & 52.193 & 2.58 & 5.19 \\
\hline 6 & 88.23 & 338.580 & 296.950 & 41.630 & 317.765 & 36.040 & 38.345 & 2.31 & 6.40 \\
\hline
\end{tabular}


Table 5. Interloborotory comparison of apporent thermal conductivity of high-temperature mineral-fiber pipe insulation. This set of specimens is restricted to only those which were not conditioned by heoting them to the highest temperotures of measurement before data was taken. Kcalc is computed from eq (12). The standard deviotion of the dato set from eq (12) for nonconditioned specimens is 4.72 percent.

\begin{tabular}{|c|c|c|c|c|c|c|c|c|c|}
\hline $\begin{array}{l}\text { Lob } \\
\text { No. }\end{array}$ & $\begin{array}{l}\text { Density } \\
\left(\mathrm{kg} / \mathrm{m}^{3}\right)\end{array}$ & $\begin{array}{c}\text { Thigh } \\
\text { (C) }\end{array}$ & $\begin{array}{l}\text { Tlow } \\
\text { (C) }\end{array}$ & $\begin{array}{r}\text { DelT } \\
(C)\end{array}$ & $\begin{array}{r}\text { Tove } \\
\text { (C) }\end{array}$ & $\begin{array}{c}K c a \mid c \\
m W /(m . K)\end{array}$ & $\begin{array}{c}\text { Kdot } \\
\mathrm{mW} /(\mathrm{m} \cdot \mathrm{K})\end{array}$ & Der & $\begin{array}{l}\text { Kder } \\
\text { (Pct) }\end{array}$ \\
\hline 2 & 86.98 & 379.261 & 302.150 & 77.111 & 340.706 & 38.252 & 38.907 & 0.65 & 1.71 \\
\hline 2 & 86.98 & 419.206 & 306.150 & 113.056 & 362.678 & 40.077 & 40.924 & 0.85 & 2.12 \\
\hline 2 & 86.98 & 523.706 & 313.817 & 209.889 & 418.761 & 47.026 & 49.426 & 2.40 & 5.10 \\
\hline 2 & 86.98 & 632.928 & 323.928 & 309.000 & 478.428 & 58.468 & 61.531 & 3.06 & 5.24 \\
\hline 3 & 94.35 & 339.261 & 299.039 & 40.222 & 319.150 & & & & 5.50 \\
\hline 3 & 94.35 & 451.483 & 306.483 & 145.000 & 378.983 & 41.781 & 44.671 & 2.89 & 6.92 \\
\hline 3 & 94.35 & 590.9 & 318.706 & 272.2 & 454.8 & 44 & 56.1 & 2.76 & 5.16 \\
\hline 3 & 94.35 & 728.150 & 334.817 & 393.333 & 531.483 & 72. & 73.491 & 0.87 & 1.20 \\
\hline 4 & & & & & & & & & \\
\hline 4 & 92.26 & 529.761 & 311.039 & 218.722 & 420.400 & 47.376 & 47.553 & 0.18 & 0.37 \\
\hline 4 & 92.26 & & 320.650 & 307.833 & 474.567 & 57.716 & 57.496 & -0.22 & -0.38 \\
\hline 4 & 92.26 & 726.539 & 332.928 & 393.611 & 529.733 & 72.195 & 68.303 & -3.89 & -5.39 \\
\hline 5 & & & & & & & & & -6.46 \\
\hline 5 & 90.13 & 429.311 & 302.256 & 127.056 & 365.783 & 40.440 & 37.466 & -2.97 & -7.35 \\
\hline 5 & 90.13 & 502.089 & 306.483 & 195.606 & 404.286 & & 41.645 & -3.39 & -7.53 \\
\hline 5 & 90.13 & 551.383 & 312.694 & 238.689 & 432.039 & 49.301 & 45.680 & -3.62 & -7.35 \\
\hline 7 & & & & & & & 38.042 & -0.02 & -0.06 \\
\hline 7 & 90.50 & 438.761 & 303.872 & 134.889 & 371.317 & 40.985 & 41.933 & 0.95 & 2.31 \\
\hline 7 & 90.50 & 493.539 & 308.428 & 185.111 & 400.983 & 44.519 & 46.256 & 1.74 & 3.90 \\
\hline 7 & 90.50 & 559.761 & 314.428 & 245.333 & 437.094 & 50.152 & 52.308 & 2.16 & 4.30 \\
\hline 7 & 90.50 & 679.150 & 327.150 & 352.000 & 503.150 & 64.668 & 65.421 & 0.75 & 1.16 \\
\hline
\end{tabular}


Toble 6. Appopent thermal conductivity of specimens of high-temperature mineral-fiber pipe insulation that were not conditioned before they were measured. The last two columns indicate deviotions of these data from the least-squares curve, eq (11), defined by specinens that were conditioned before they were measured. The standard deviation of the data set from eq (11) for conditioned specimens is 5.40 percent.

\begin{tabular}{|c|c|c|c|c|c|c|c|c|c|}
\hline $\begin{array}{l}\text { Lob } \\
\text { No. }\end{array}$ & $\begin{array}{l}\text { Density } \\
\left(\mathrm{kg} / \mathrm{m}^{3}\right)\end{array}$ & $\begin{array}{l}\text { Thigh } \\
\text { (C) }\end{array}$ & $\begin{array}{l}\text { Tlow } \\
\text { (C) }\end{array}$ & $\begin{array}{r}D e I T \\
(C)\end{array}$ & $\begin{array}{r}\text { Tove } \\
\text { (C) }\end{array}$ & $\begin{array}{c}\text { Keolc } \\
\mathrm{mw} /(\mathrm{m} \cdot \mathrm{k})\end{array}$ & $\begin{array}{c}\text { Kdat } \\
m w /(m \cdot k)\end{array}$ & Der & $\begin{array}{l}\text { Kder } \\
\text { (Pct) }\end{array}$ \\
\hline 2 & 86.98 & 379.261 & 302.150 & 77.111 & 340.706 & 37.881 & 38.907 & 1.03 & 2.71 \\
\hline 2 & 86.98 & 419.206 & 306.150 & 113.856 & 362.678 & 40.519 & 40.924 & 0.41 & 1.00 \\
\hline 2 & 86.98 & 523.706 & 313.817 & 209.889 & 418.761 & 48.173 & 49.426 & 1.25 & 2.60 \\
\hline 2 & 86.98 & 632.928 & 323.928 & 309.000 & 478.428 & 57.942 & 61.531 & 3.59 & 6.19 \\
\hline 3 & 94.35 & 339.261 & 299.039 & 40.222 & 319.150 & 35.461 & 38.907 & 3.45 & 9.72 \\
\hline 3 & 94.35 & 451.483 & 306.483 & 145.000 & 378.983 & 42.617 & 44.671 & 2.85 & 4.82 \\
\hline 3 & 94.35 & 590.928 & 318.706 & 272.222 & 454.817 & 53.877 & 56.199 & 2.32 & 4.31 \\
\hline 3 & 94.35 & 728.150 & 334.817 & 393.333 & 531.483 & 68.226 & 73.491 & 5.26 & 7.72 \\
\hline 4 & 92.26 & 439.706 & 303.761 & 135.944 & 371.733 & 41.687 & 40.492 & -1.20 & -2.87 \\
\hline 4 & 92.26 & 529.761 & 311.039 & 218.722 & 420.400 & 48.455 & 47.553 & -0.90 & -1.86 \\
\hline 4 & 92.26 & 628.483 & 320.650 & 307.833 & 474.567 & 57.305 & 57.496 & 0.19 & 0.33 \\
\hline 4 & 92.26 & 726.539 & 332.928 & 393.611 & 529.733 & 67.904 & 68.303 & 0.40 & 0.59 \\
\hline 5 & 90.13 & 404.283 & 297.822 & 106.461 & 351.053 & & 36.601 & -2.53 & -6.46 \\
\hline 5 & 90.13 & 429.311 & 302.256 & 127.856 & 365.783 & 40.934 & 37.466 & -3.47 & -8.47 \\
\hline 5 & 90.13 & 502.089 & 306.483 & 195.606 & 404.286 & 46.119 & 41.645 & -4.47 & -9.70 \\
\hline 5 & 90.13 & 551.383 & 312.694 & 238.689 & 432.039 & 50.238 & 45.680 & -4.56 & -9.07 \\
\hline 7 & 90.50 & 375.650 & 300.261 & & & & & & 1.26 \\
\hline 7 & 90.50 & 438.761 & 303.872 & 134.889 & 371.317 & 41.633 & 41.933 & 0.30 & 0.72 \\
\hline 7 & 90.50 & 493.539 & 308.428 & 185.111 & 400.983 & 45.625 & 46.256 & 0.63 & 1.38 \\
\hline 7 & 90.50 & 559.761 & 314.428 & 245.333 & 437.094 & 51.018 & 52.308 & 1.29 & 2.53 \\
\hline 7 & 90.50 & 679.150 & 327.150 & 352.000 & 503.150 & 62.576 & 65.421 & 2.85 & 4.55 \\
\hline
\end{tabular}




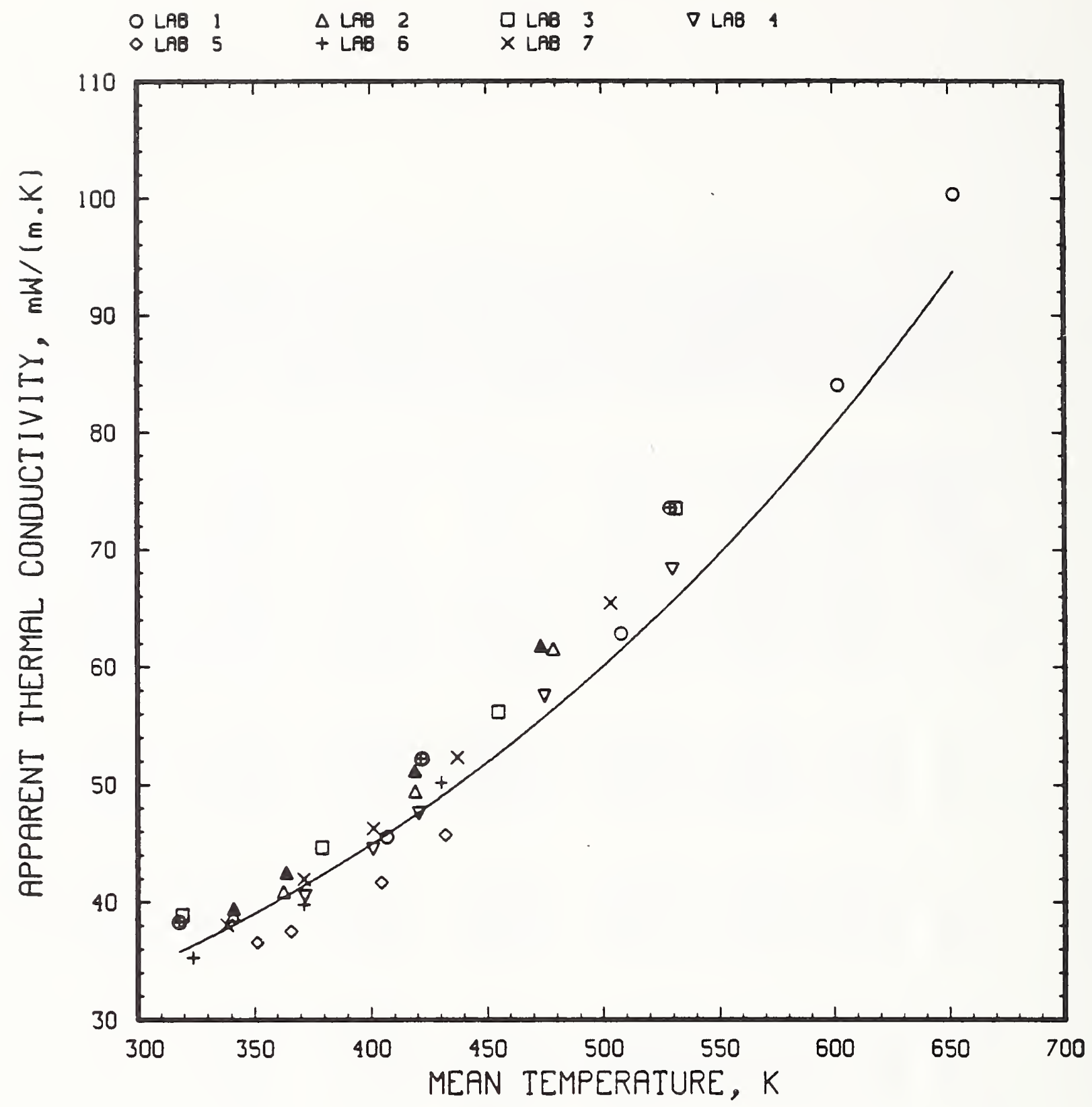

Figure 1. Interlaboratory comparison of apparent thermal conductivity of mineral-fiber pipe insulation measured on the horizontal pipetest apparatus. The nominal density of the specimens is $90 \mathrm{~kg} / \mathrm{m}^{3}(5.6$ $\left.16 / \mathrm{ft}^{3}\right)$. Measurements were performed in oir ot ambient pressure. The solid line is a plot of eq $(9)$. thermal conductivity as a function of temperature. Each point on this line represents the thermal conductivity determined by the local thermal gradient (vonishing temperature difference), at o point within the specimen; the temperature at that point is given by the value from the temperature axis. Eoch symbol represents the experimental conductivity obtained at (large) non-zero temperature differences between the boundary surfaces at Tcold and Thot. The value of conductivity at the symbol is the ratio of the integral of the conductivity function between Tcold and Thot to the corresponding temperature difference. For this reason the data points deviate from the curve when large temperature differences are used. Specimens from laboratories 1. 2. 4 and 6 were conditioned by heating specimens to the highest temperatures of measurement before taking data. Filled triangles denote repeated measurements by laboratory 2 and circled "plus" signs denote repeot measurements by laboratory 6 . 


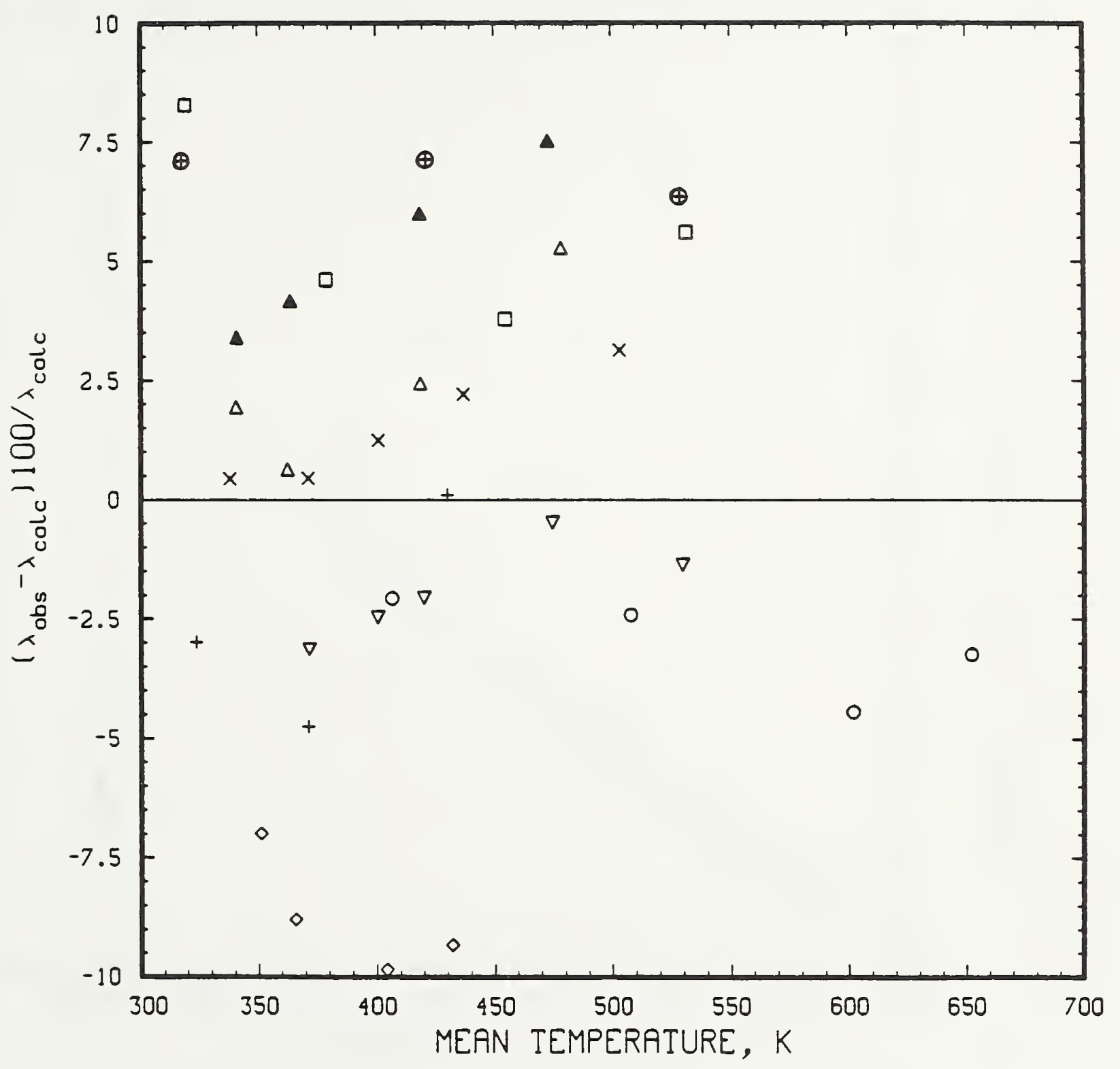

Figure 2. Deviotions of apparent thermal conductivity of mineral-fiber pipe insulotion, as measured by all seven participants. from values calculated with eq (9). thermal conductivity as a function of temperature. Each experimental conductivity value is obtained at (lorge) nonzero temperature differences between the boundory surfoces of Tcold and Thot. The integral of the conductivity function is computed over the temperoture interval from Tcold to Thot. We compute the ratio of this integral to the corresponding temperature difference to obtain the mean conductivity over the interval from Tcold to Thot. The difference between the computed mean and the experimental value is the deviotion. Filled triongles denote repeoted meosurements by loboratory 2, and circled plus signs denote repeoted measurements by laboratory 6 . 


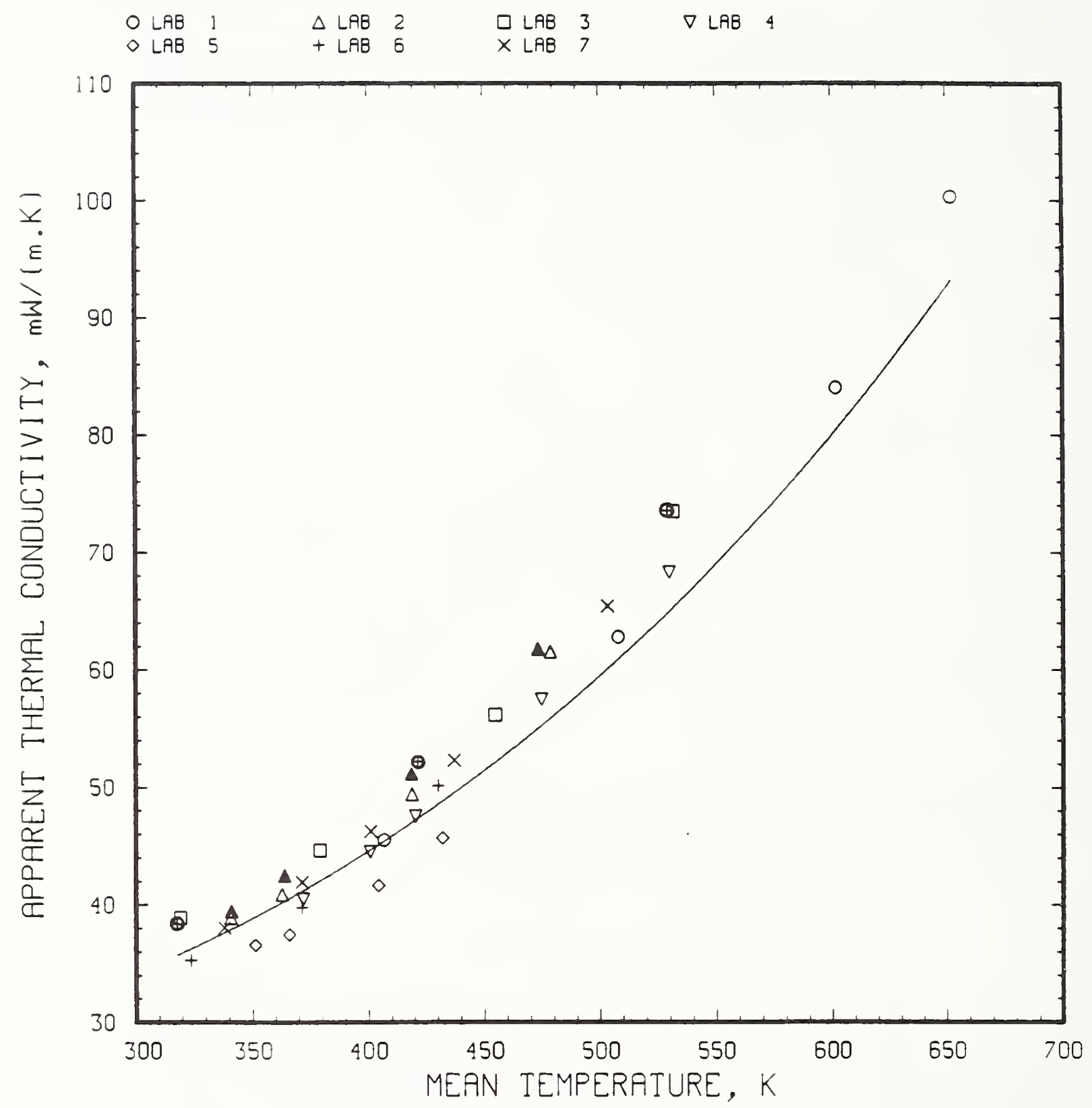

Figure 3. Interloborotory comporison of opporent thermal conductivity of mineral-fiber pipe insulation measured on the horizontol pipetest opporotus. Meosurements were performed in air ot ambient pressure. The solid line is o plot of eq (10). for thermal conductivity os a function of temperoture, obtained by weighting eoch loboratory equally. Specimens from laborotories 1.2. 4, and 6 were conditioned by heoting specimens to the highest temperotures of meosurement before toking dota. Filled triangles denote repeated measurements by laboratory 2 and circled plus signs denote repeated measurements by laboratory 6 . Please see the coption of figure 1 for on explanotion of the difference between the experimental points (symbols) and the fitted conductivity function. 


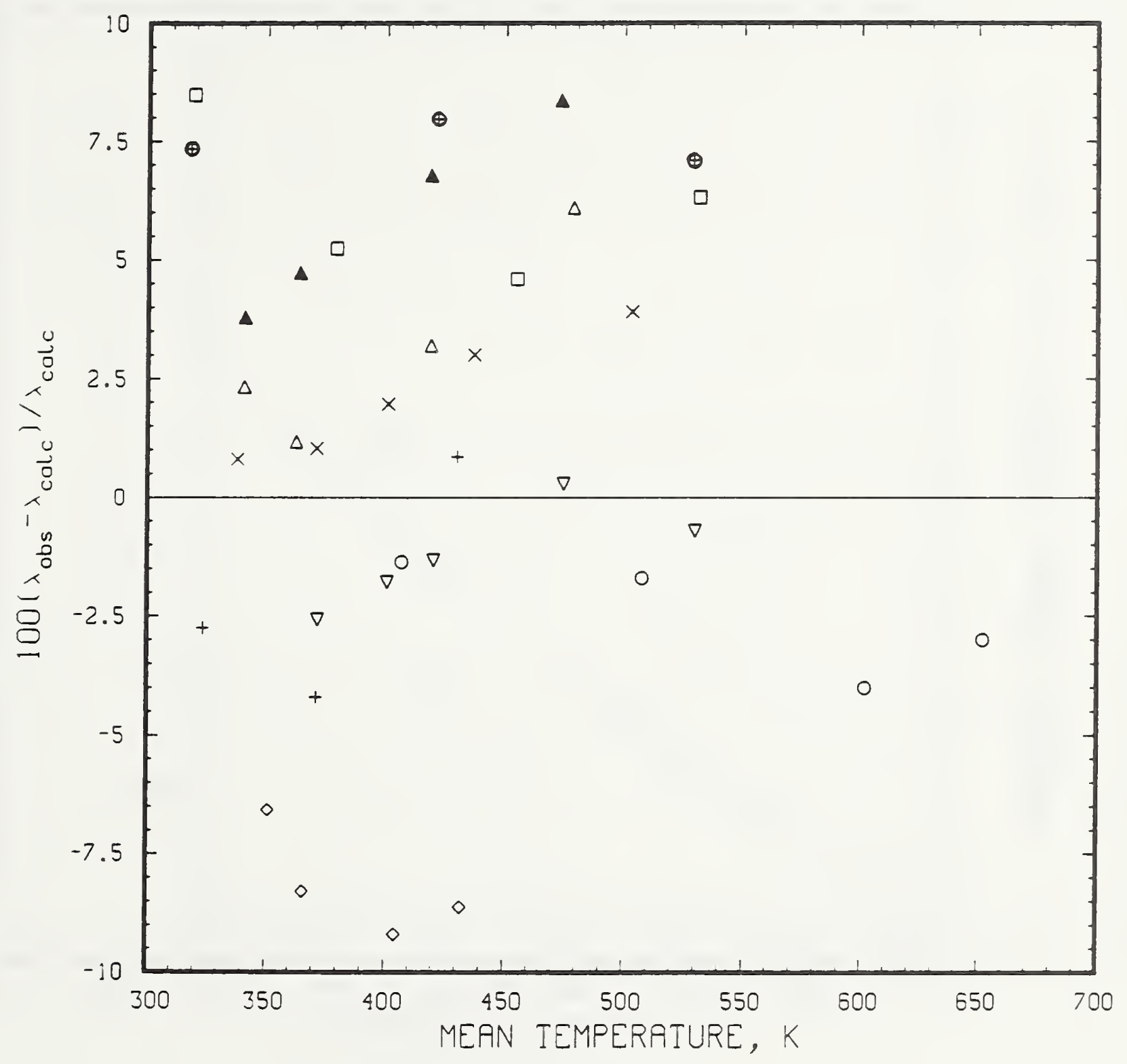

Figure 4. Deviotions of apporent thermal conductivity of minerol-fiber pipe insulation, as measured by all seven participonts, from values calculated with eq (10) obtained by weighting eoch laboratory equally. Filled triongles denote repeoted measurements by laboratory 2 , and circled plus signs denote repeat measurements by laboratory 6 . Please see caption of figure 2 for on explanation of how the deviation is computed. 


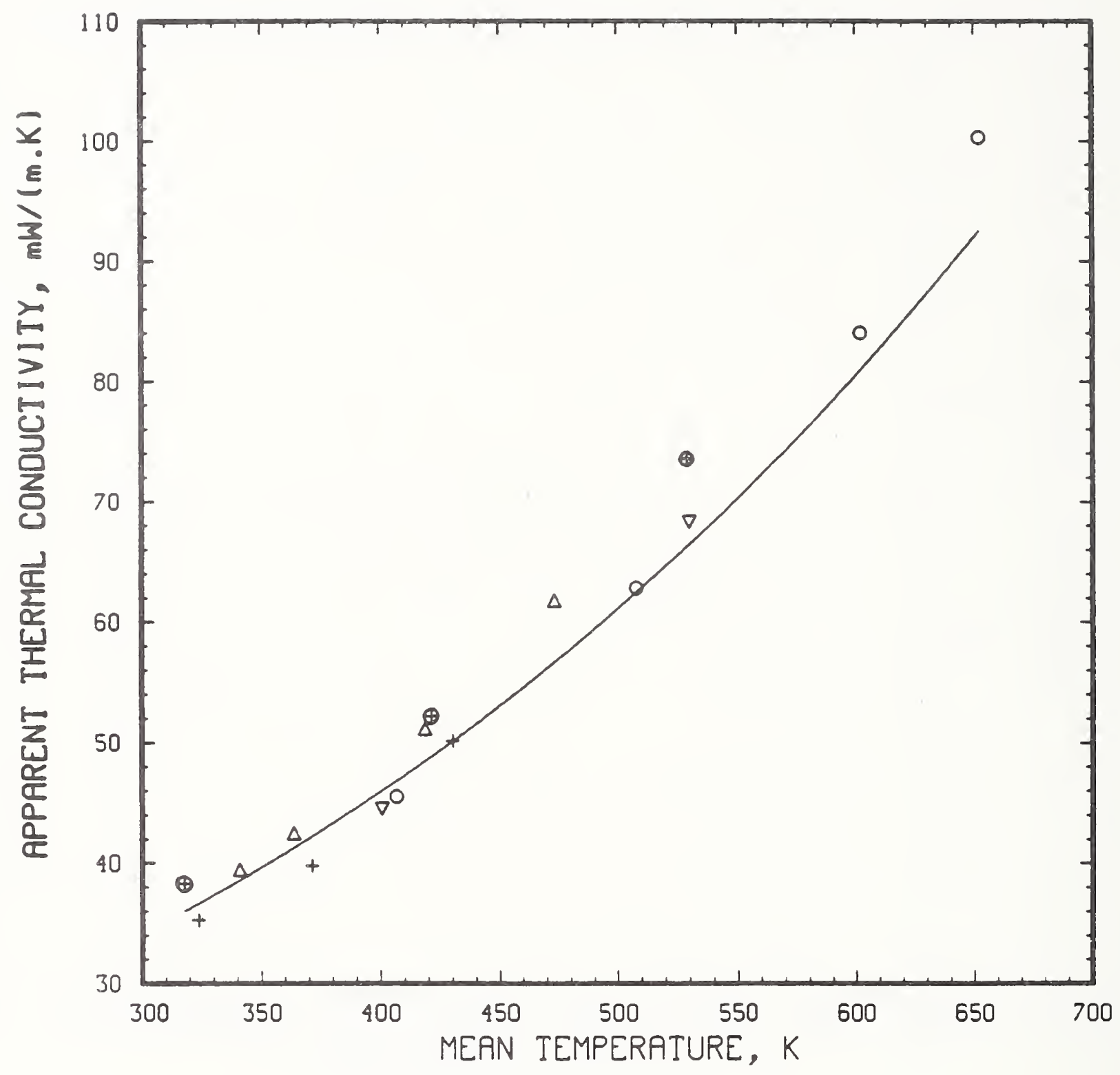

Figure 5. Interlaboratory comparison of apparent thermal conductivity - of mineral-fiber pipe insulation measured on the horizontal pipetest apparatus. Measurements were performed in air at ambient pressure. Specimens were conditioned by heating them to the highest temperatures of measurement before taking data. The solid line is a plot of eq (11) for thermal conductivity as a function of temperature. Please see the caption of figure 9 for an explanation of the difference between the experimental points (symbols) and the fitted conductivity function. 


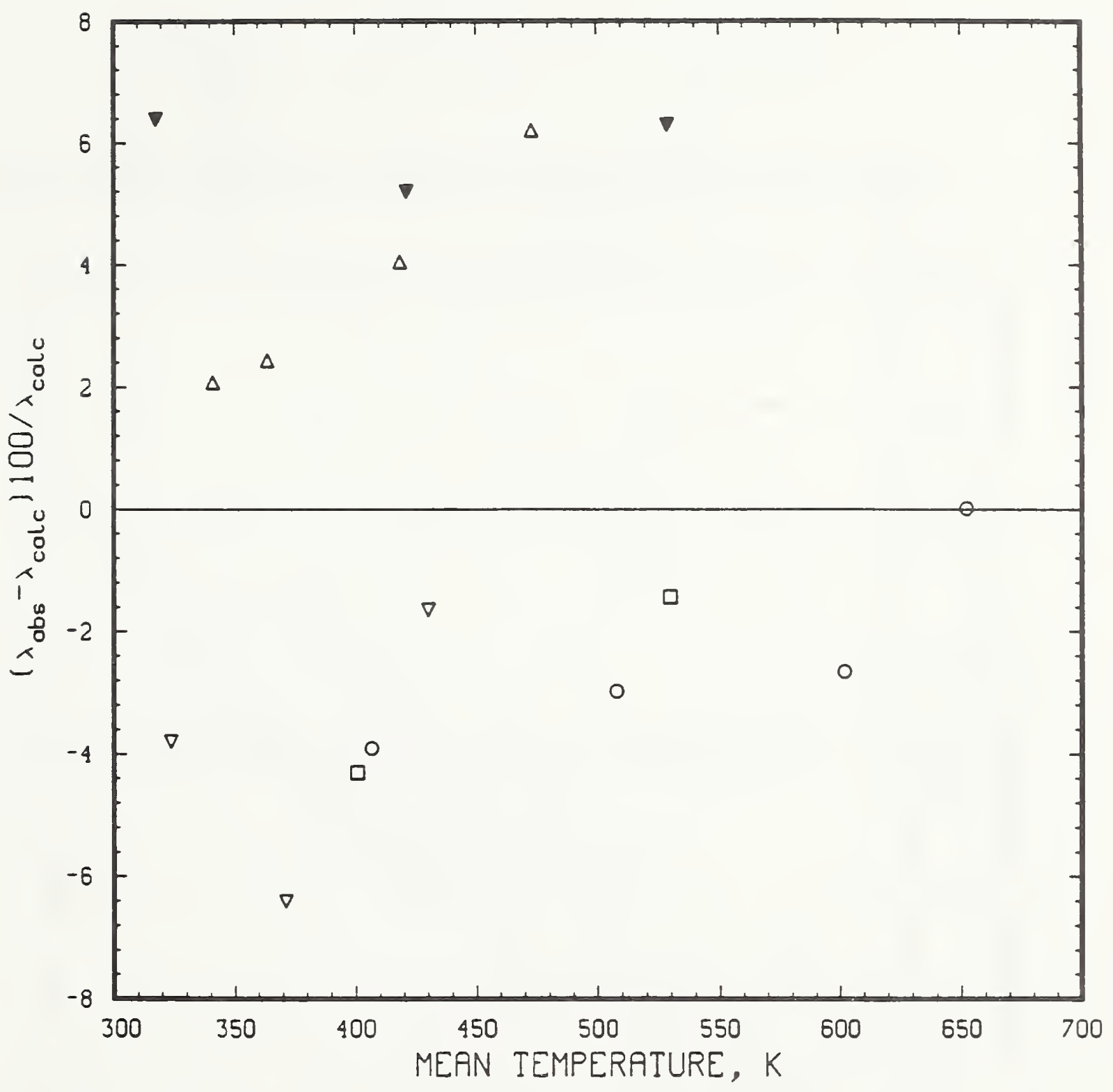

Figure 6. Deviotion of opporent thermal conductivity of mineral-fiber pipe insulation. os meosured ofter conditioning, from values calculated with eq (11). Open squares represent dato from loborotory 4; downwardpointing triongles represent data from laborotory 6 . Filled triongles are repeoted meosurements by laboratory 6 . As before, open circles represent dato of laboratory 1. and upward-pointing triangles are doto of laboratory 2. Please see coption of figure 2 for an explanotion of how the deviation is computed. 


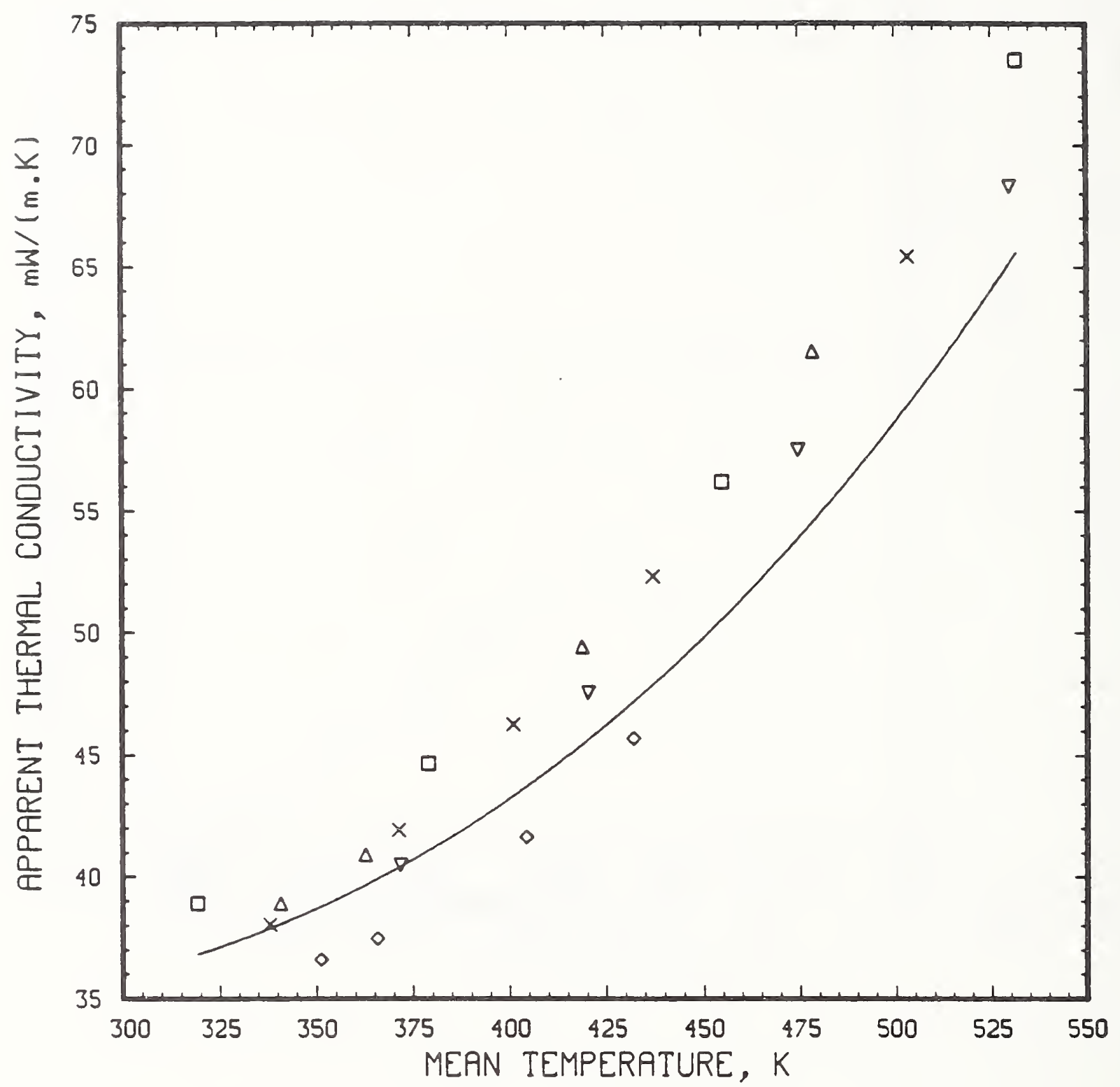

Figure 7. Apporent thermal conductivity of specimens of mineral-fiber pipe insulation that were not conditioned before they were meosured. Meosurements were performed in air at ombient pressure and over the ronge of mean temperotures from 318 to $531 \mathrm{~K}$. The solid line is o plot of eq (12) for thermal conductivity as a function of temperature. Please see the caption of figure 1 for an explonation of the difference between the experimental points (symbols) and the fitted conductivity function. 


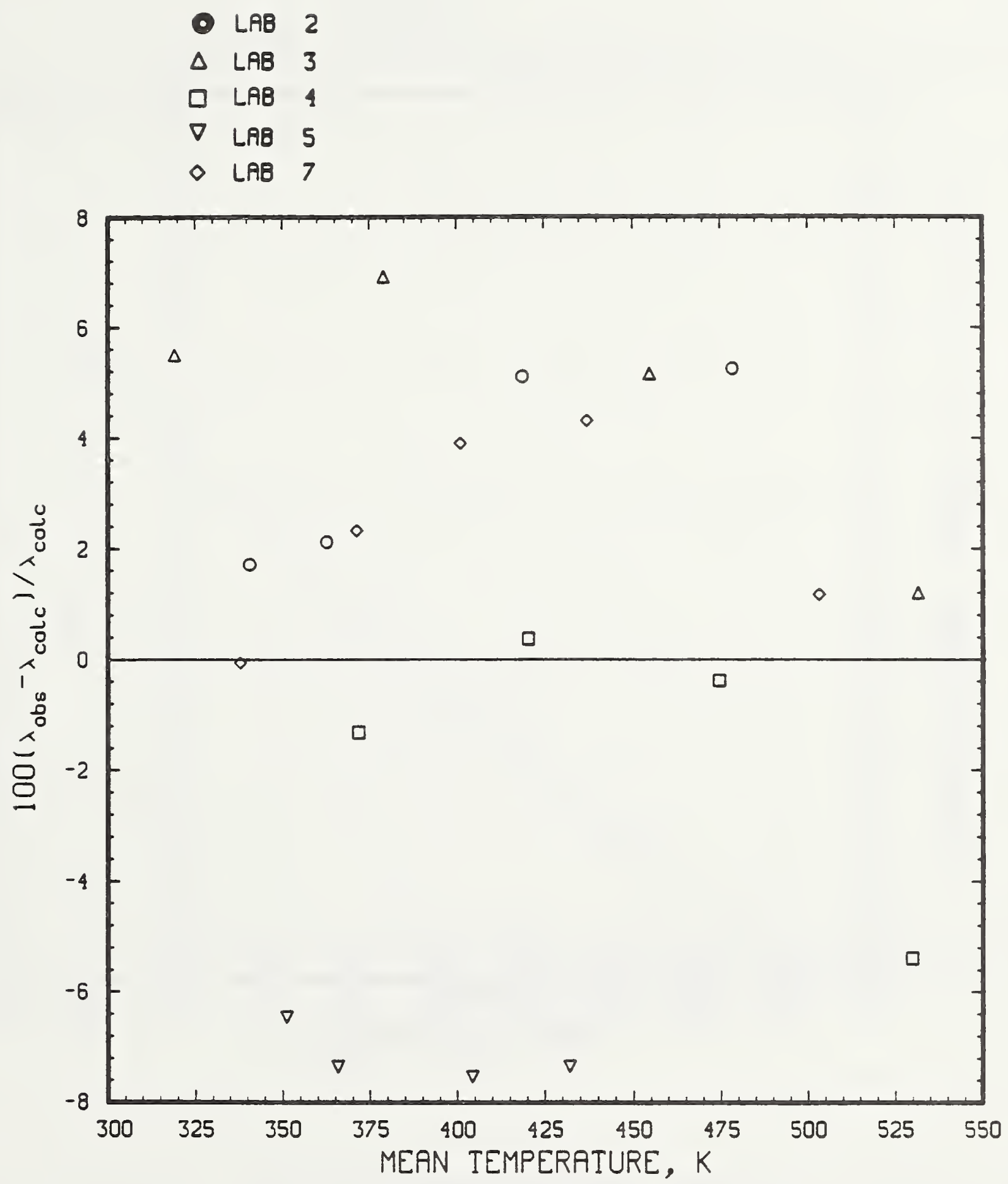

Figure 8. Deviations of apparent thermal conductivity of mineral-fiber values calcu insulation. not conditioned before being measured, from values calculated with eq $(1 \overline{2)}$. Please see caption of figure 2 for an explanotion of how the deviation is computed. 


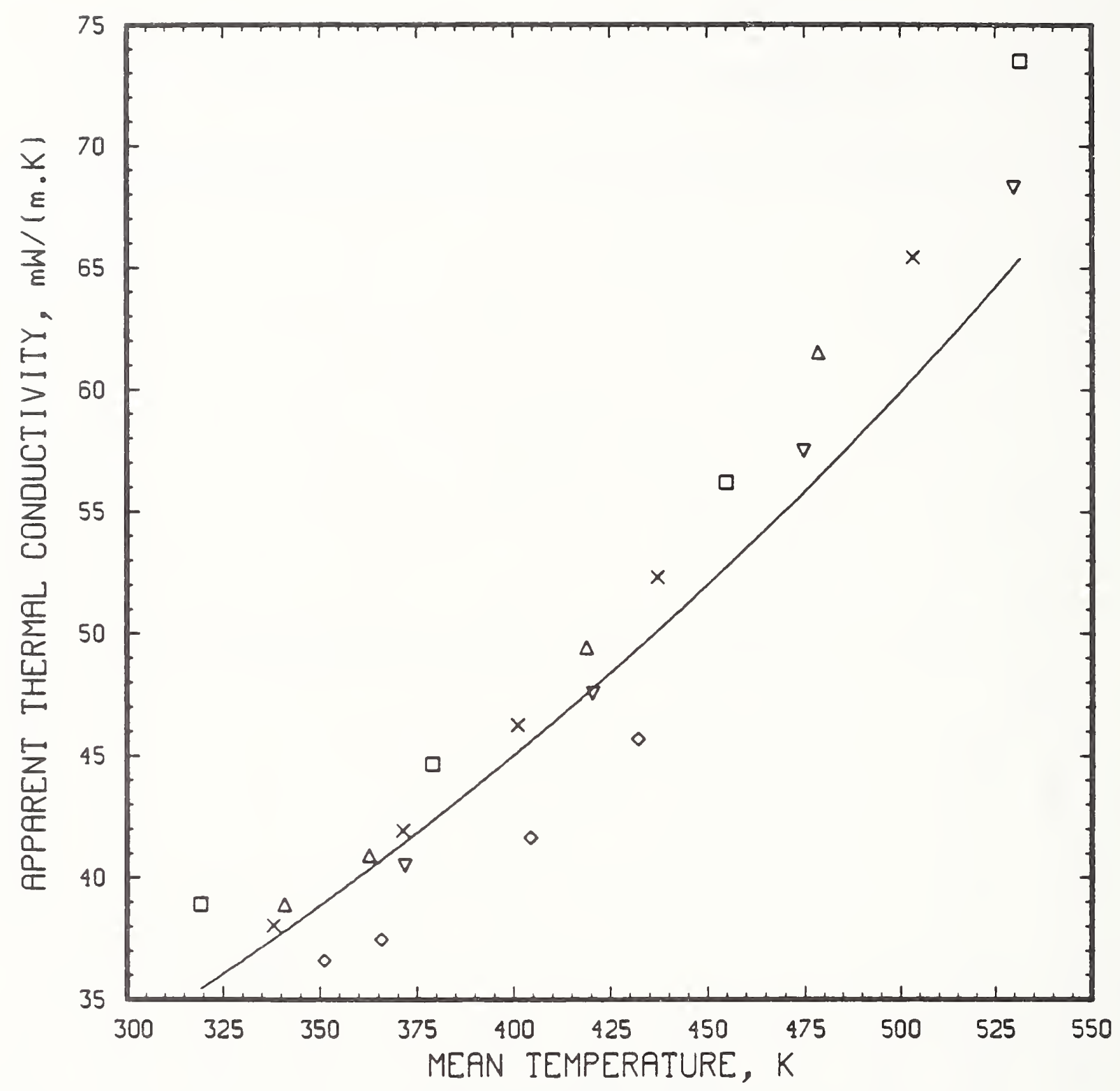

Figure 9. Apporent thermal conductivity of specimens of minerol-fiber - pipe insulation that were not conditioned before they were measured. Meosurements were performed in air at ambient pressure. The The solid line is a plot of eq (11). thermal conductivity as a function of temperature, for specimens that were conditioned before they were measured. The position of the solid line was adjusted vertically to minimize the rms deviation of this dato from the curve. Please see the coption of figure 1 for an explanation of the difference between the experimental points (symbols) and the fitted conductivity function. 


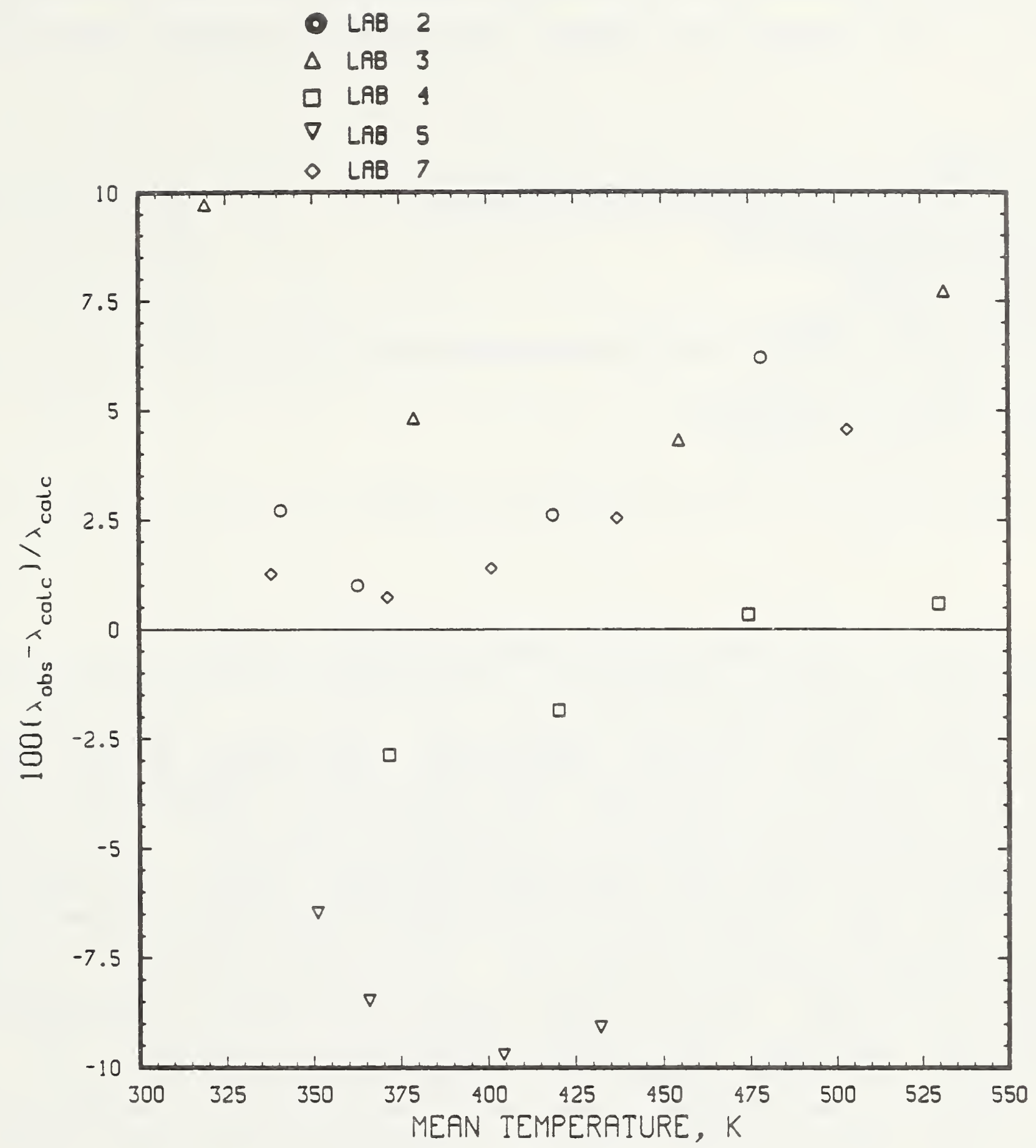

Figure 10. Deviations of apparent thermal conductivity of mineral-fiber pipe insulation. not conditioned before being measured, from values calculoted with eq $(1 \overline{1)}$, the relation for thermal conductivity of specimens that were conditioned. Pleose see caption of figure 2 for on explanation of how the deviotion is computed. 


\begin{tabular}{|c|l|l|l|}
\hline $\begin{array}{c}\text { U.S. DEPT. OF COMM. } \\
\text { BIBLIOGRAPHIC DATA } \\
\text { SHEET (See instructions) }\end{array}$ & $\begin{array}{l}\text { 1. PUBLICATION OR } \\
\text { REPORT NO. } \\
\text { NISTIR 89-3913 }\end{array}$ & 2. Performing Organ. Report No. & $\begin{array}{c}\text { 3. Publication Date } \\
\text { Apri1 } 1989\end{array}$ \\
\hline
\end{tabular}

4. TITLE AND SUBTITLE

INTERLABORATORY COMPARISON OF THE GUARDED HORIZONTAL PIPE-TEST APPARATUS

Precision of ASTM Standard Test Method C-335 Applied to Mineral-Fiber Pipe Insulation

5. AUTHOR(S)

David R. Smith

6. PERFORMING ORGANIZATION (If joint or other than NBS, see instructions)

National Institute of Standards and Technology

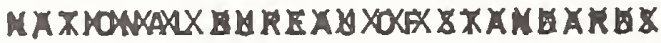

DEPARTMENT OF COMMERCE

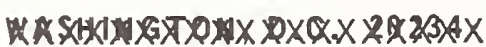

Gaithersburg, MD 20899

9. SPONSORING ORGANIZATION NAME AND COMPLETE ADDRESS (Street. City. State, ZIP)

U.S. Department of Energy

Oak Ridge National Laboratory

Oak Ridge, Tennessee 37830

10. SUPPLEMENTARY NOTES

Document describes a computer program; SF-185, FIPS Software Summary, is attached.

11. ABSTRACT (A 200-word or less factual summary of most significant information. If document includes a significant bibliography or literature survey. mention it here)

Apparent thermal conductivity of refractory pipe insulation from the same production lot was measured by seven different laboratories. The purpose of this intercomparison was to assess the precision and bias of the ASTM Test for Measurement of Steady-State Heat-Transfer Properties of Horizontal Pipe Insultation (C 335). Four laboratories submitted conductivity measurements for conditioned specimens. The test results for thermal conductivity of the four conditioned specimens include the temperature range from 318 to $652 \mathrm{~K}$ and $i 17$ ustrate the interlaboratory reproducibility as well as the temperature dependence of the conductivity. The standard deviation of the data from each participating laboratory was measured by their deviation from a polynomial function fitted to all data. For the 16 test results from the four laboratories that conditioned their specimens, the standard deviation was 4.3 percent. For a 11 test results from a 17 seven participants, the standard deviation was 5 percent. This value is offered as the estimated precision of the horizontal pipe-test method. The accuracy of this pipe-test method cannot be estimated from the data obtained in this intercomparison.

12. KEY WORDS (Six to twelve entries; alphabetical order: capitalize only proper names; and separate key words by semicolons) accuracy; apparent thermal conductivity; bias; guarded hot plate; high temperature; horizontal pipe; insulation; interlaboratory comparison; mineral fiber; precision; standard text method

13. AVAILABILITY

X] Unlimited

For Official Distribution. Do Not Release to NTIS

Order From Superintendent of Documents, U.S. Government Printing Office, Washington, D.C. 20402.

14. NO. OF PRINTED PAGES

XX Order From National Technical Information Service (NTIS), Springfield, VA. 2216I 
• 
